\title{
العلاقة بين ممارسة العلاج الواقعي في خدمة الفرد والتخفيف من حدة القلق الاجتماعي للمراهقين مجهولي النسب
}

\author{
إعداد

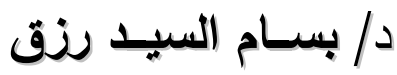

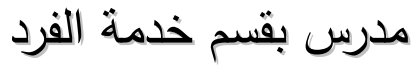 \\ المعهد العالي للخدمة الاجتماعية

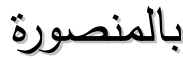


تعتبر مرحلة المراهقة من أهم مراحل النمو وأكثرها إثراءً في حياة الإنسان ، فهي تشكل مرحلة انتقال بين الطفولة والرشد ، وهي بحق فترة التغيرات المتمايزة التي ثتبلور خلالها الثخصية وتأخذ ملامحها الثابتة ، ومن هنا فإن الاهنمام بالثربية والرعاية خلال هذه المرحلة يجب ألا يقل عن الاهنمام بثربية الأطفال ( 1 ( ). فالإنسان يمر بمراحل من النمو والنطور ويواجه في كل مرحلة من مراحل النمو النفسي والاجتماعي بتحديات ومشكلات وعليه أن يتجاوزها لتحقيق السلامة النفسية ، والمراهقة كمرحلة نمائية تعد من أخطر مراحل عمر الإنسان ولا نغالي إذا قلنا أنها سن الأزمات ونتهح بدايات المشاغبة والجنوح وإدمان العقاقير ، وظهور السلوكيات العدوانية وكثير من الاضطرابات النفسية والعقلية من بينها القلق والاكتثاب والفصام ، وتلعب تغيرات المراهق الجسمية والنفسية والعقلية والانفعالية

دوراً في زيادة مشكلات المراهقين ومعاناتهم ( r ). وعلى الرغم من أن المراهق يرغب في التشبث بوجوده مطالباً بالاستقلا عن الأسرة ، وشق طريق جديد ورسم خط جديد له في الحياة ، وعلى الرغم من الثورات والاحتجاجات التي يعلنها من وقت لآخر ضد القيود الموجودة أو القيود التي بلي بلهي يتوهمها بالأسرة ، إلا أنه يرتكز عليها وجدانياً واقتصادياً واجنماعياً وينطلق منها باستمرار، والواقع الذي ينبغي للوالدين إدراكه باستمرار هو أن المراهق يستثف أمنيته ووجوده الفردي من الوجود الجماعي للأسرة (r" ). لذلك فإن للأسرة دوراً كبيراً في تتشئة المراهق سلباً وإيجاباً وكذلك في نموه الاجتماعي ، فالأسرة الهادئة تعكس هذه وده الثقة في حياة المراهق وتتبع حاجاته إلى الطمأنبنة والأمن ، وبالتالي سوف يكون لها الأثز الايجابي على سلوكه ونظرته

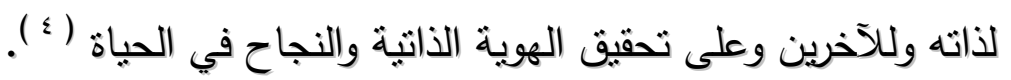
كما أن الأسرة نسق اجتماعي رئيسي ومصدر الأخلاق والدعامة الأولى لضبط السلوك ، والإطار الذي يتلقي فيه الإنسان أول دروس الحياة الاجتماعية ، وبالرغم من صغر حجمها إلا أنها تعثبر من أقوى أنساق المجتمع فعن طريقها يكتسب الإنسان إنسانيته وفيها يتحول المولود من كائن بيولوجي إلى مخلوق اجتماعي يعيش في انسجام مع الآخرين وفقاً للقيم والمعايير القائمة (0 ( ). وبؤكد ذلك على أهمية وضرورة أن يعيش الطفل وينواجد في كنف أسرته الطبيعية ، إلا أن هناك العديد من الحالات

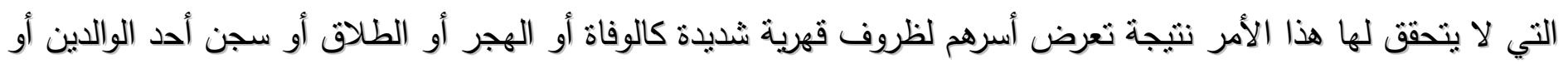
كليهما أو غيرها من الظروف والأوضاع التي تؤدي عامة إلى تصدع وانهيار البناء الأسري ، الأمر الذي يترتب عليه

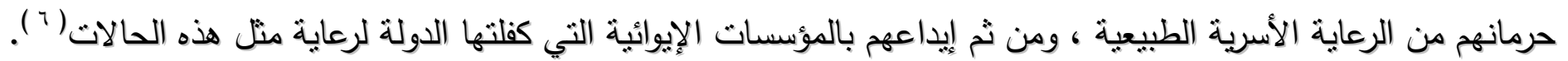
وتهدف هذه المؤسسات بكافة أنواعها إلى توفير الرعاية الاجتماعية والنفسية والصحية لمختلف الفئات المودعين بها

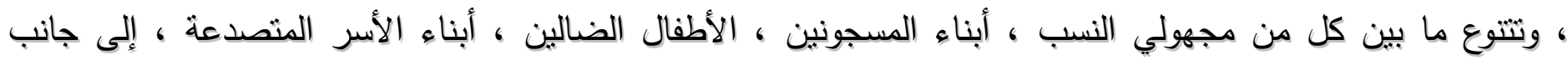

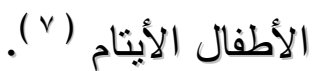


هذا وقد أوضحت العديد من الدراسات أن المودعين بالمؤسسات الإيوائية يعانون من العديد من المشكلات النفسية

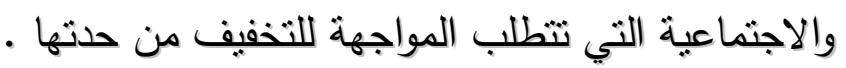
فقد أثنارت دراسة عزه حسين (1910) أن المحرومين من الرعاية الأسرية يعانون من مشكلات سلوكية بنسبة أكبر

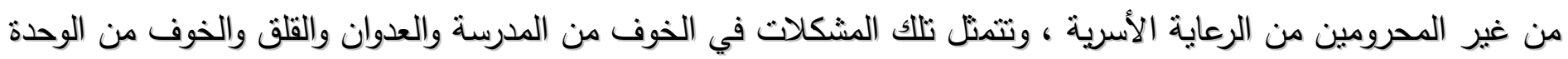

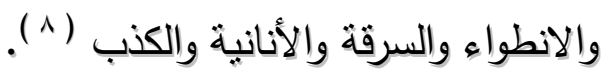

كذلك دراسة يوسف عبد الفتاح (ب991) أشارت إلى أن المحرومين من الرعاية الأسرية يكونون أقل شعوراً بالأمن

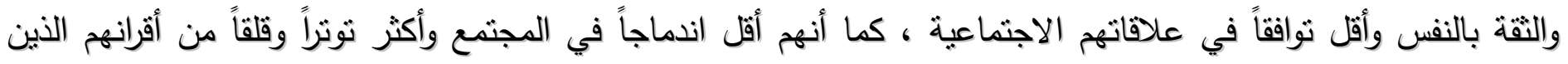

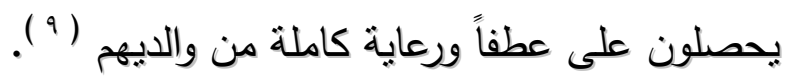
كما أظهرت دراسة كلاً من باربرا وجيدث Barbara, Judith (1990 (1) أن المحرومين من الرعاية الأسرية يعانون

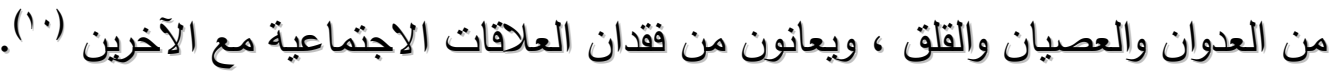

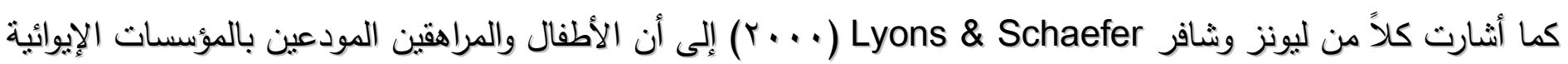

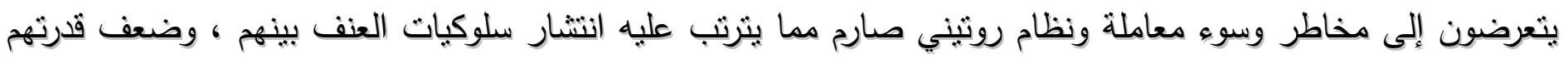

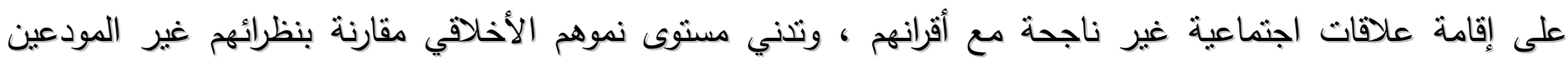
بالمؤسسات الإيوائية (11)

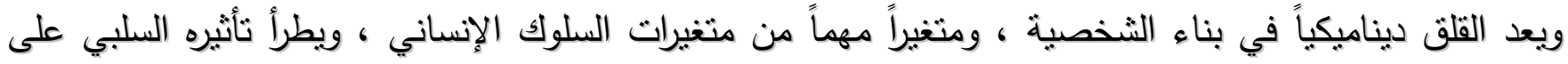

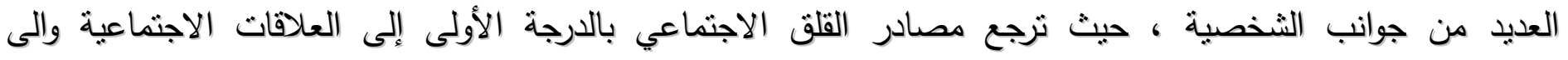

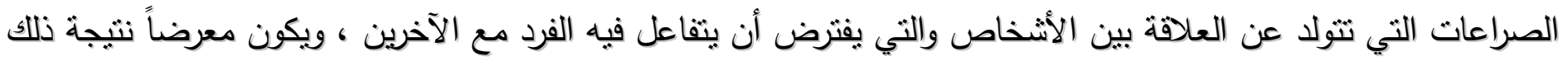
إلى نوع من أنواع النقيبيم (r'). والقلق الاجتماعي هو" حالة من التوتر نتنج عن القلق أو الحدوث الفعلي للإتقييم في مواقف التفاعل الثخصي وفيها

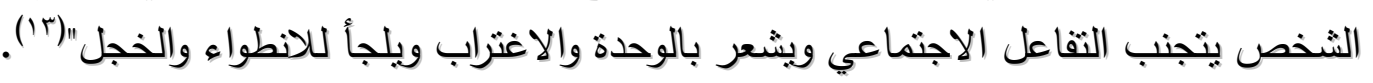

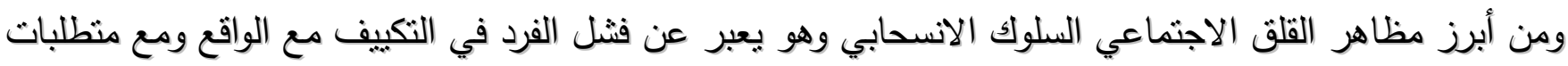

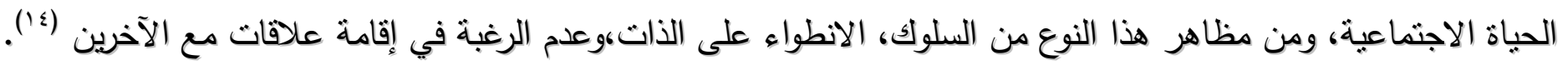

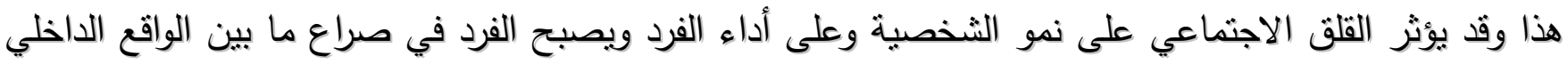

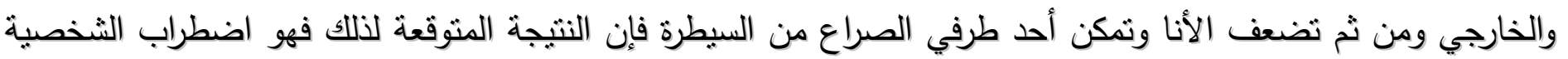
وانخفاض مستوى السواء (10) والأفراد المصابون بالقلق الاجتماعي يشعرون بالارتباك والورطة في المواقف الاجتماعية وخوف من أن الآخرين

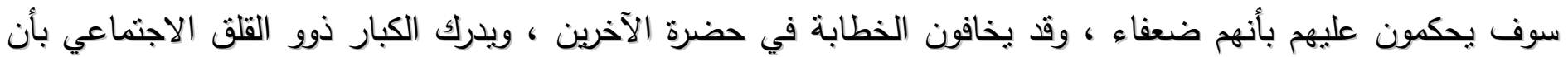

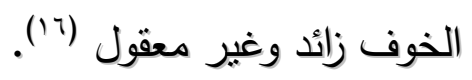

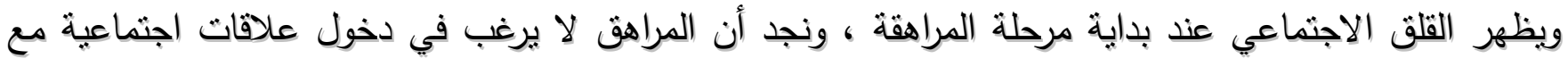

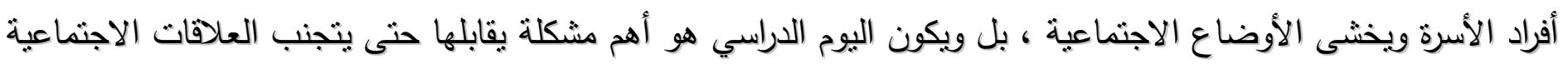


، كما يعترف المراهق بأن خوفه مبالغ فيه ، والمراهقين لا يمكنهم مناقثة أي أسئلة من المعلمين بسبب مخاوفهم وخوفاً من

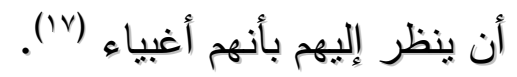
كما أن في مرحلة المراهقة يوجد العديد من العوامل التي لها نأثثير كبير على مستوى القلق الاجتماعي كالتغيرات

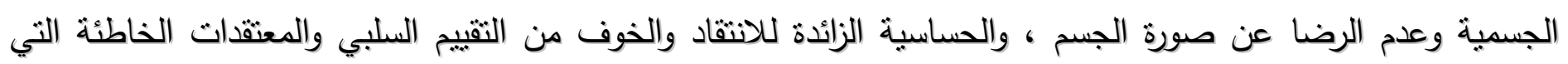

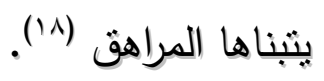
ويهنم أخصائي خدمة الفرد برعاية ومساعدة جميع الفئات التي يعمل معها في مواجهة الصعوبات التي تفوق أدائهم

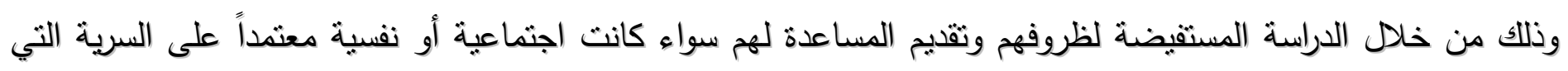

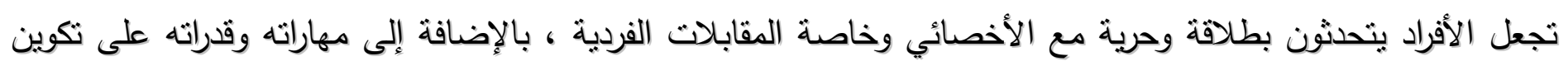

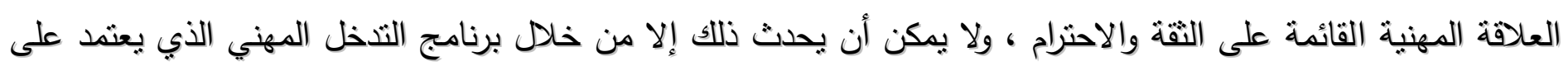

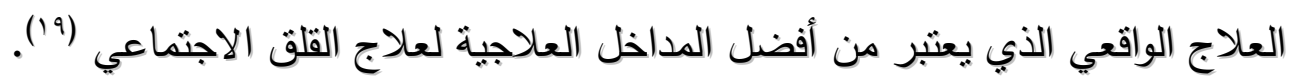
والعلاج الواقعي هو مدخل قصير العلاج لاضطرابات الثخصية من خلال المواجهة الدافئة بالواقع باعثباره حقيقة وسبيل

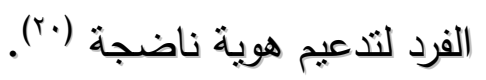
والهدف في العلاج الواقعي هو مساعدة العملاء على تحمل المسئولية الثخصية ، والمسئولية تعني القدرة على الثى

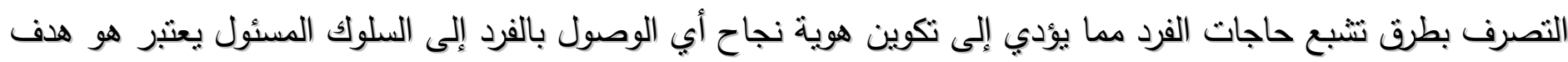

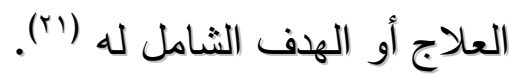
ويركز العلاج الواقعي على حل المشكلات وعلى التكيف مع منطلبات الواقع في المجتمع ، وبالتالي يؤكد العلاج

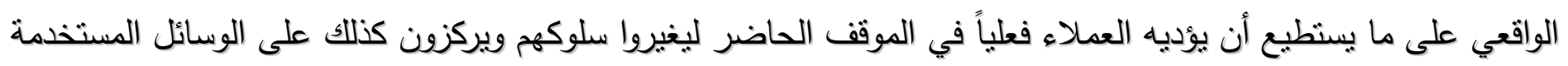

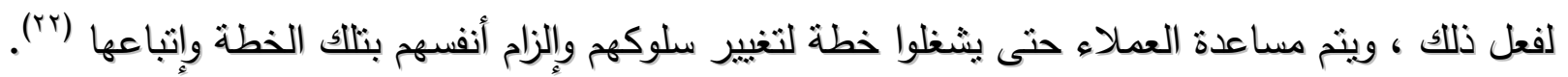

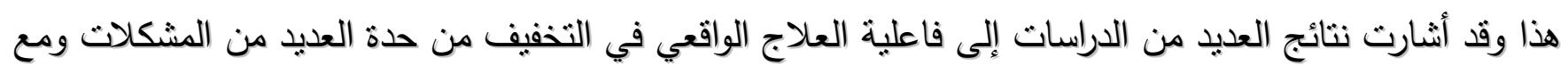

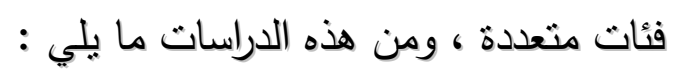

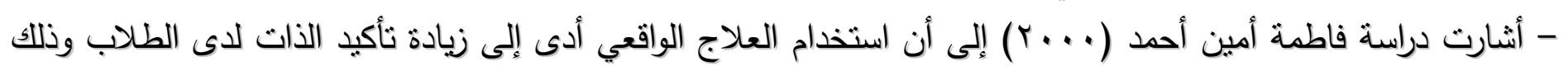

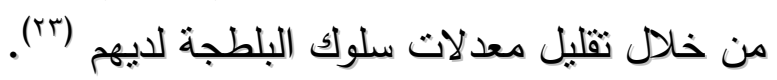

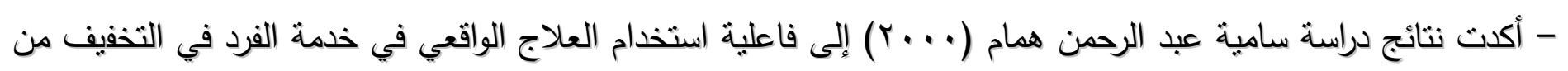

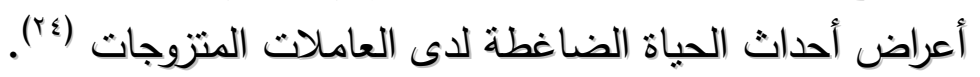

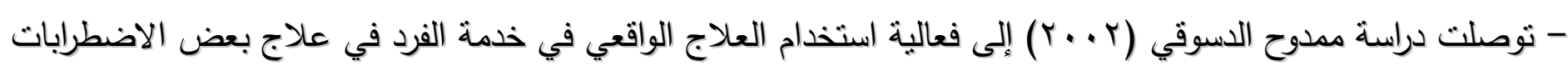
السلوكية للأطفال المساء إليهم (ror).

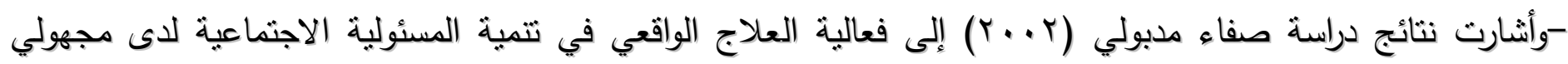
النسب (ri).

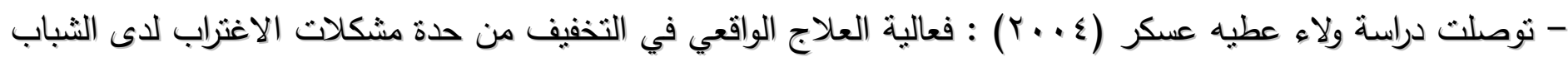
الجامعي (YV) 


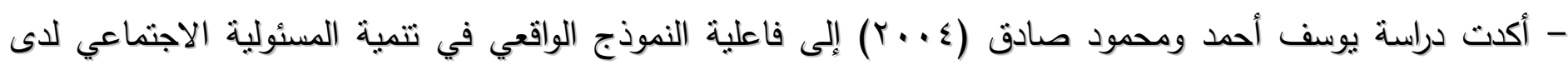

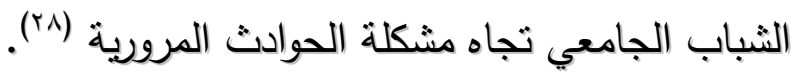

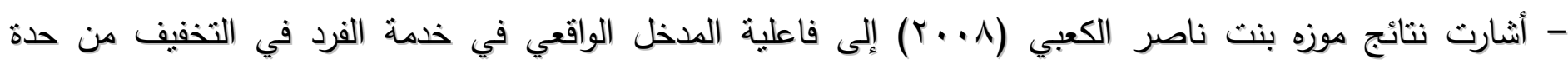
المشكلات الاجنماعية لدى المرأة المطلقة (ب9). - توصلت دراسة محمد فاروق غانم (T) (1) إلى فاعلية العلاج الواقعي في خدمة الفرد في تحسين نوعية الحياة للمرأة العاملة (r.). هذا ويوجد العديد من الدراسات السابقة المرتبطة بموضوع الدراسة الحالية ، وقد نم تقسيمها إلى دراسات مرثبطة بالقلق الاجتماعي ، ودراسات مرتبطة بمجهولي النسب :

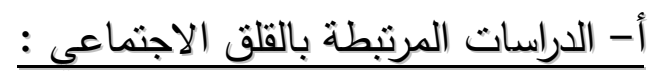

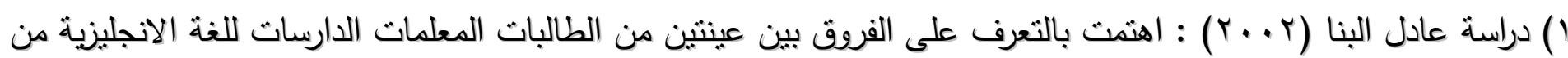

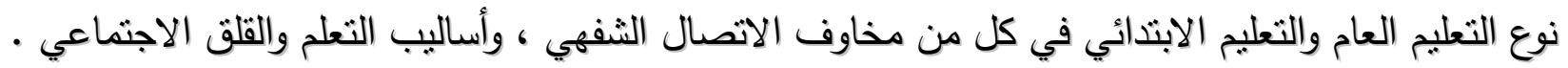

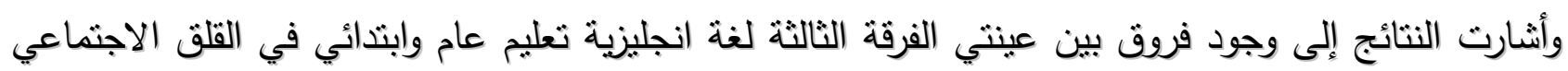

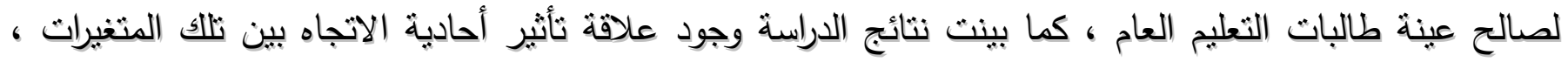

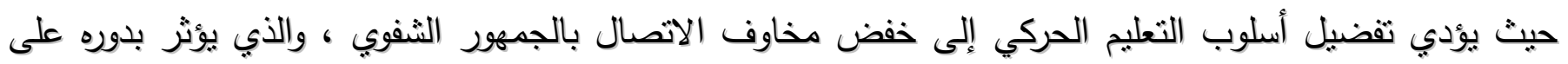

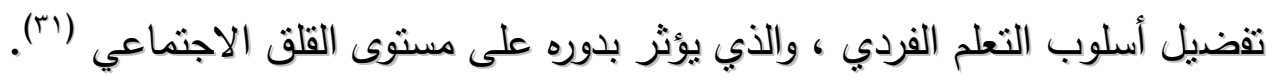

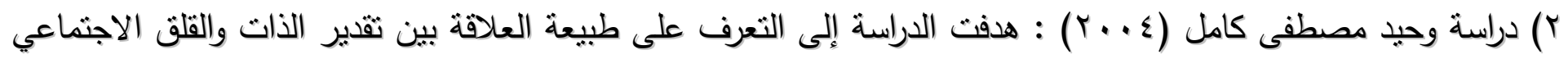

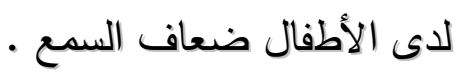

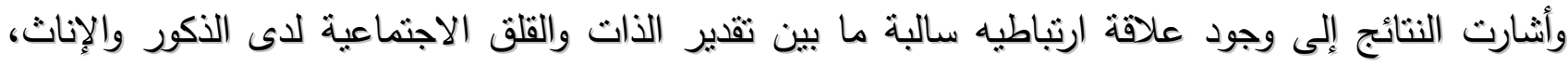

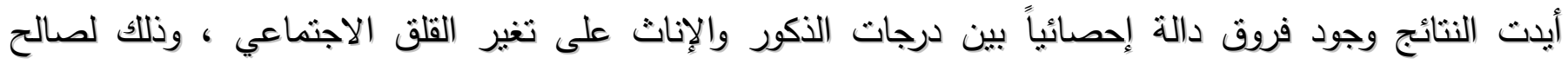

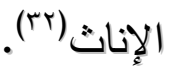

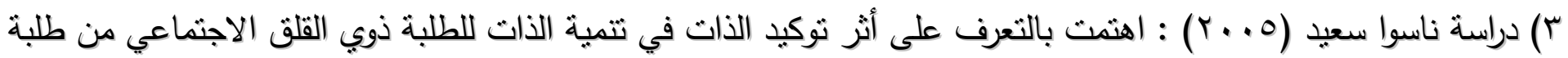

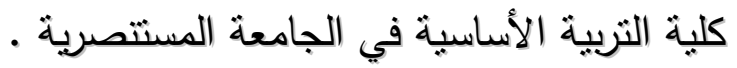
وأثنارت النتائج إلى وجود ارتباط عكسي بين فاعلية الذات والقلق الاجتماعي ، أب أنه كلما تمتع الفرد بفاعلية

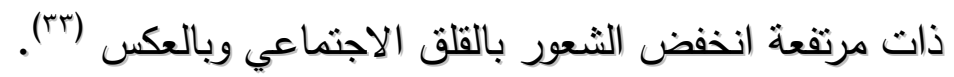

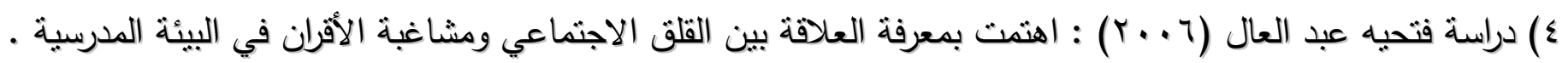

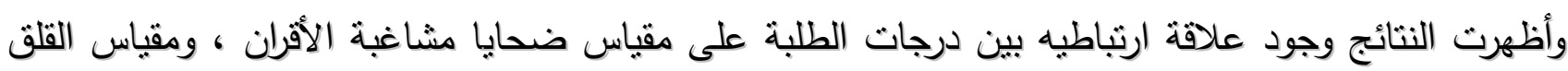

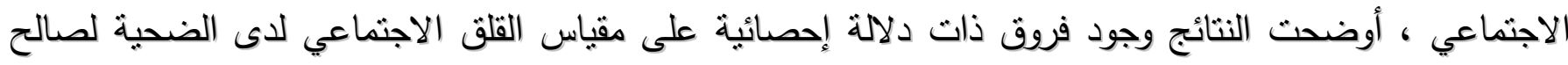

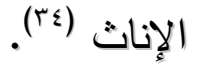

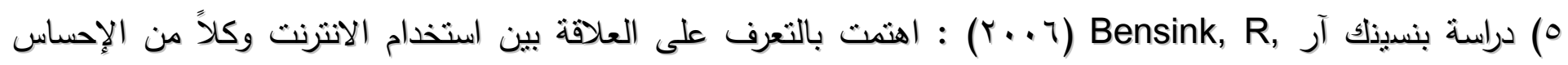
بالهوية والقلق الاجتماعي لدى المراهقين . دران 
وأثنارت النتائج إلى وجود علاقة ارتباطيه موجبة دالة إحصائيا بين القلق الاجتماعي وإدمان الانترنت ، كما

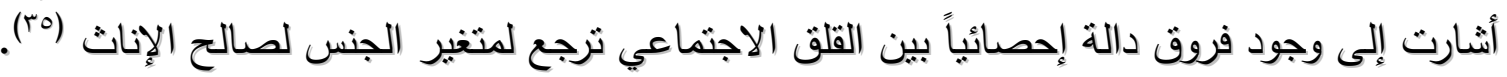
7) دراسة ابكنس سي .Epkins Cواهتمت بالتعرف على العلاقة بين القلق الاجتماعي وعدم الثعور بالطمأنينة لدى الأطفال كما يعبر عنها الأطفال والولدين .

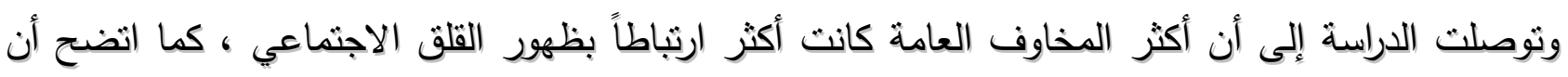

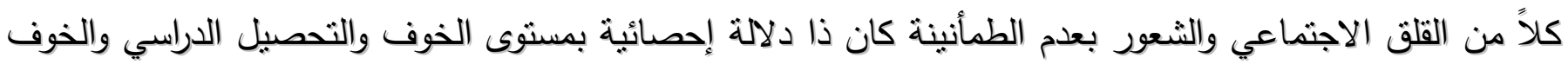

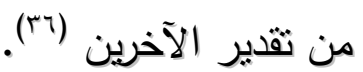

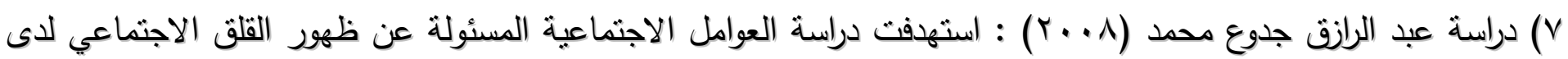

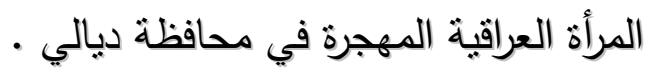

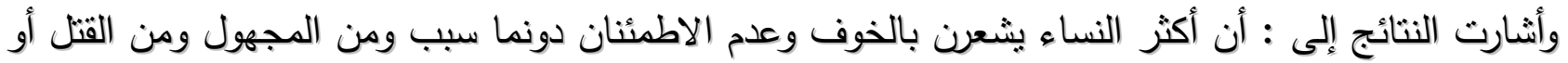

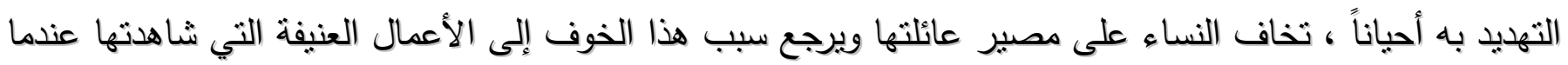

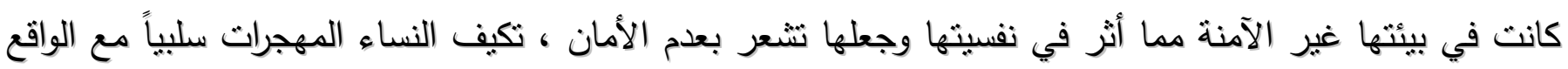

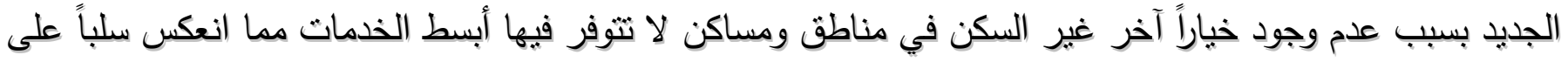
نفسيتها وجعلها تشعر بعدم الارتياح (rv)

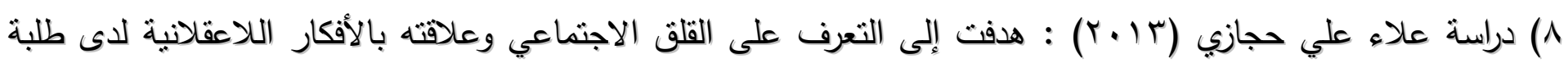

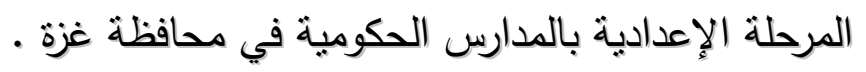
وأثنارت النتائج إلى : وجود علاقية ارتباطبه موجبة بين القلق الاجتماعي والأفكار اللاعقلانية أي أنه كلما

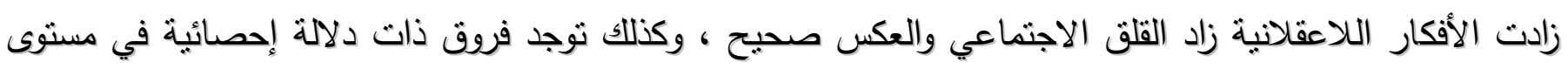

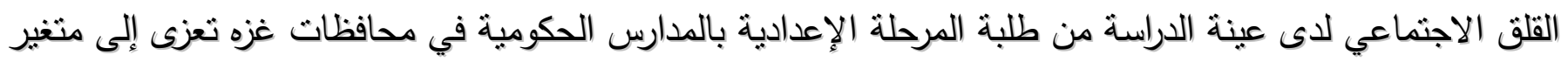

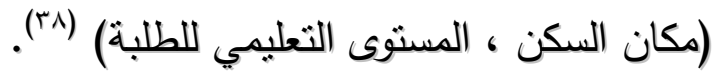

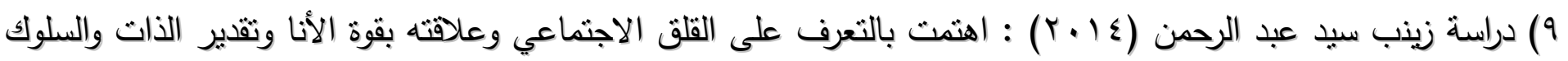

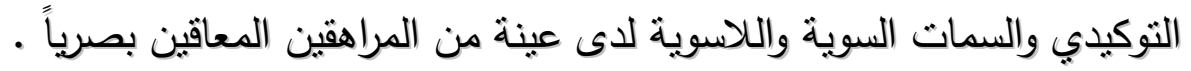

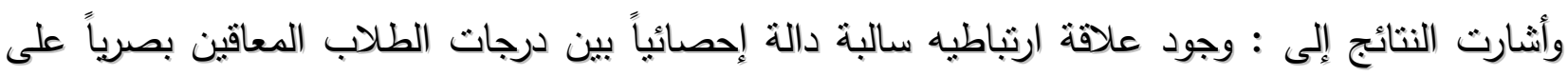

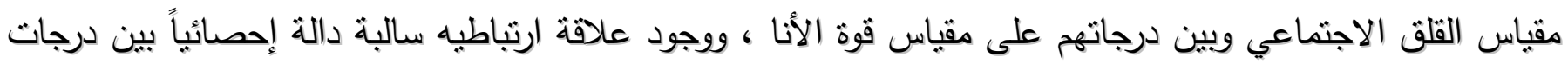

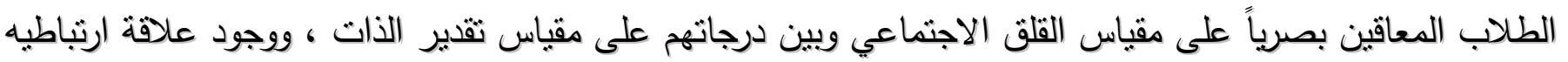

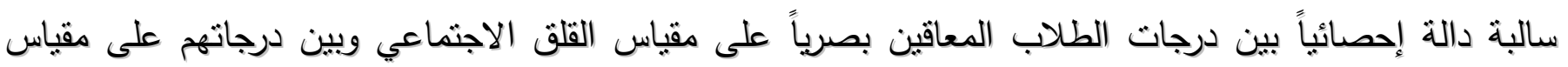

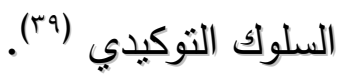
ب- دراسات مرنبطة بمجهولى النسب : درئي ( ) دراسة كوهين يتشيسكت Cohen Yecheskiet (199V) : الهتمت بتحديد مستوى الرعاية الاجتماعية لمجهولي النسب بمؤسسات الرعاية الاجتماعية . 
وأنشارت النتائج إلى: أن مجهولي النسب بعانون من الفردية والانفصال عن البيئة، وعدم القدرة على الارتباط

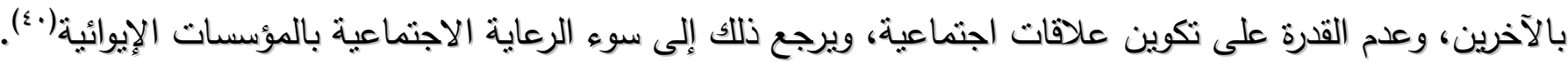

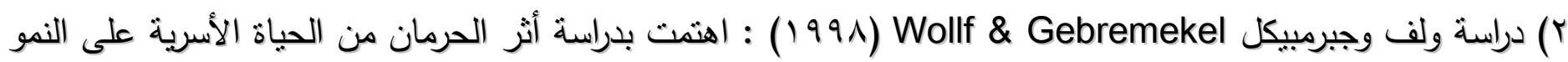

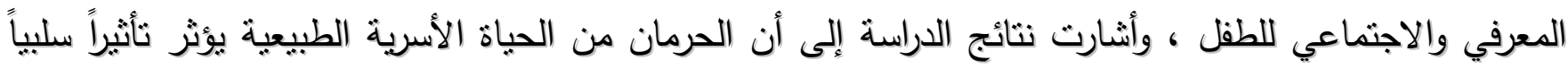

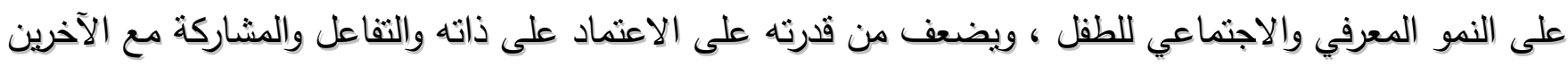

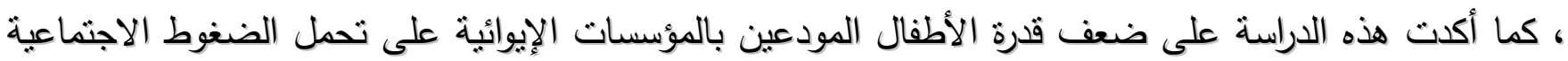

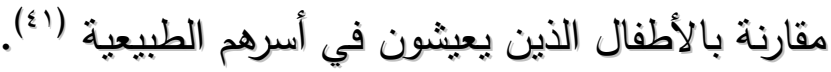

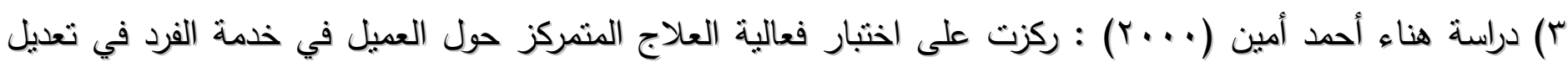

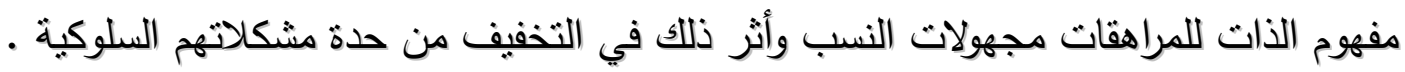

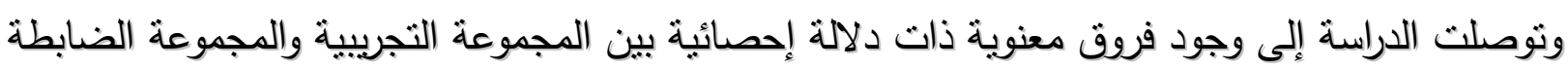

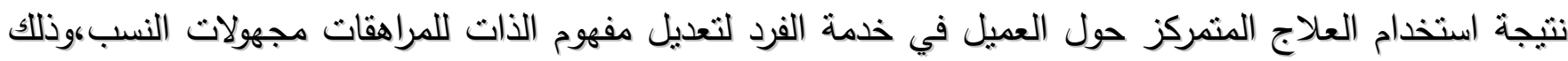

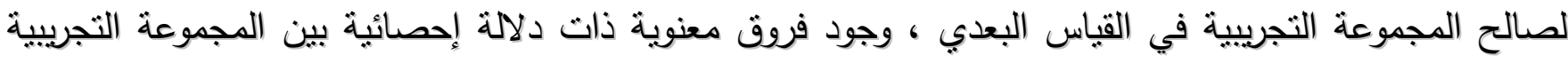

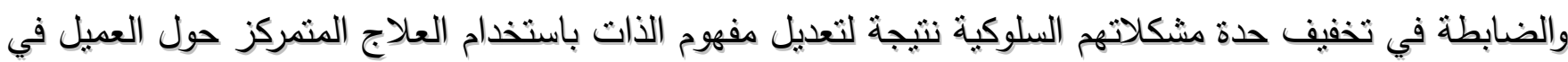

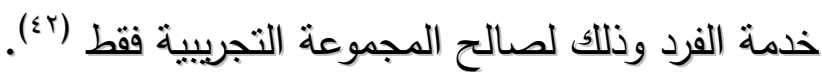

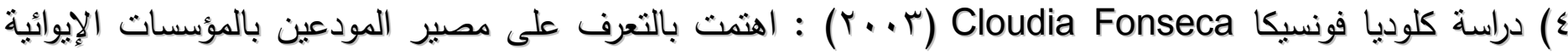
والذين يحرمون من البيئة العائلية .

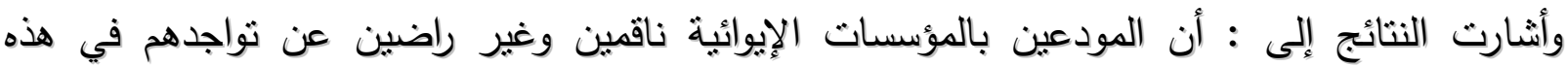

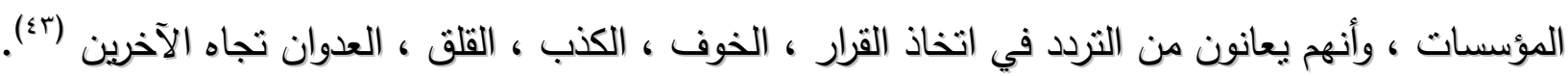

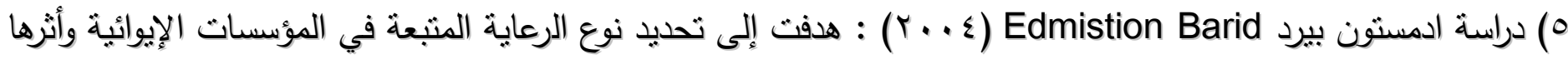

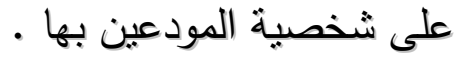
وأنثارت النتائج إلى : المودعين بالمؤسسات الإيوائية الذين يلتحقون بالمدارس خارج المؤسسة لديهم قدر

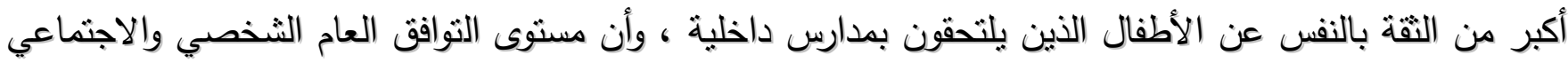
للمودعين بالمؤسسات الإيوائية يختلف من مؤسسة لأخرى وذللك يرجع لاختلاف مسنوى الرعاية المتبعة في كل مؤسسة على حدا (؛ ؟).

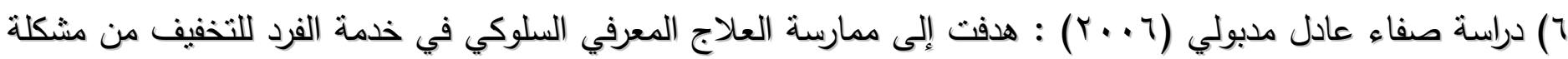
اضطراب العلاقات الاجتماعية للأطفال المعرضين للانحراف .

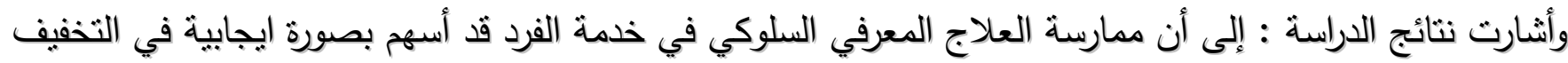

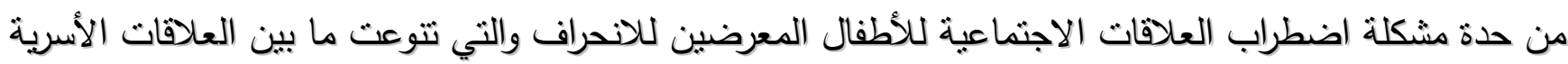

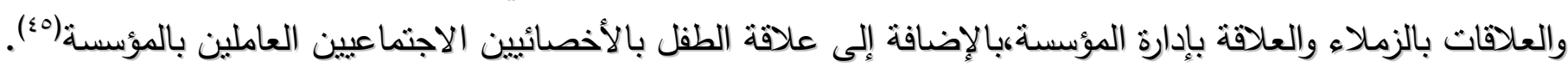

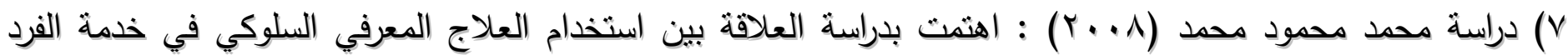
وتعديل السلوك اللاتوافقي للفتيات مجهولات النسب . 
وأثنارت النتائج إلى : فاعلية العلاج المعرفي السلوكي في تعديل السلوك اللاتوافقي للفتيات مجهولات النسب ، وقد تضمن ذلك تعديل كل من سلوك الأداء المستقل ، والتكيف الثخصي والتكيف الاجتماعي لدى الدئ الفتيات

عينة الدراسة (1٪).

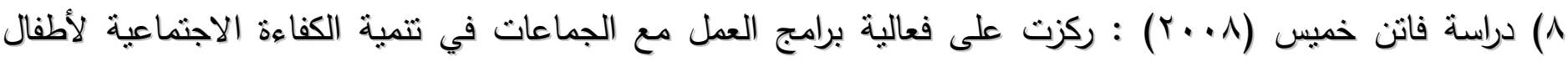

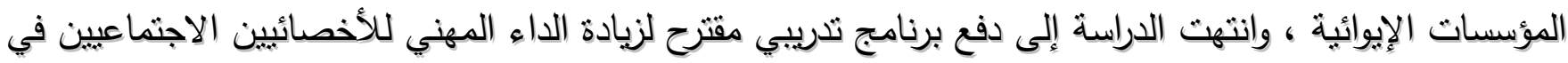

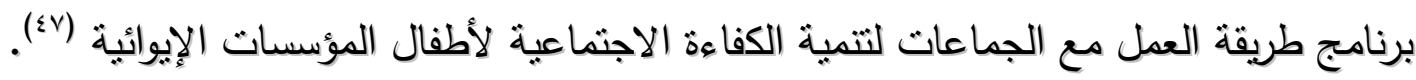

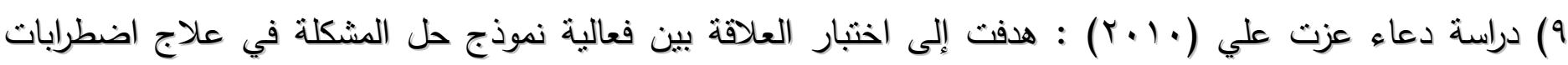

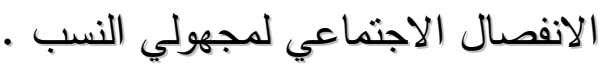

وقد توصلت الدراسة إلى وجود علاقة إحصائية ذات دلالة إحصائية بين ممارسة نموذج حل المشكلة

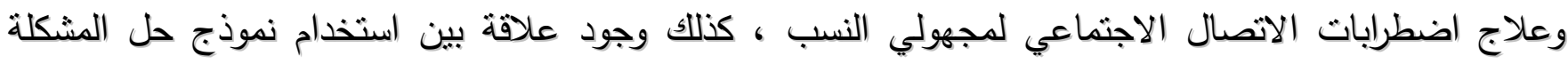
وزيادة كل من (التفاعل - المشاركة - نكوين العلاقات الاجتماعية) لمجهولي النسب تجاه (الزملاء - الإدارة -

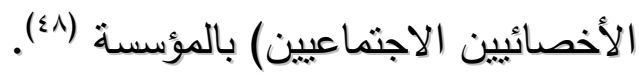

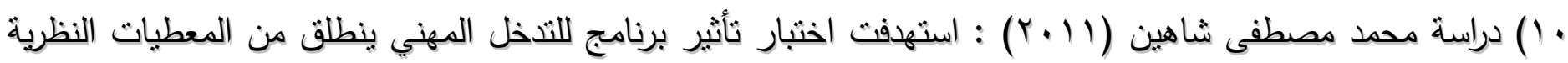

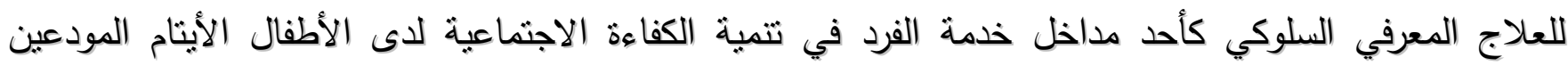
بالمؤسسات الإيوائية .

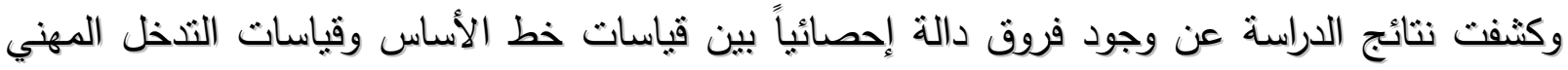

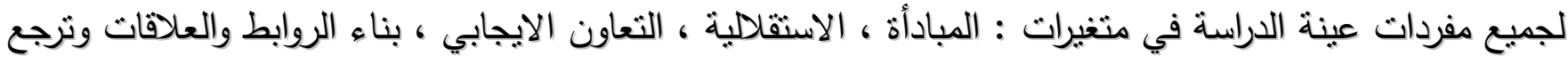

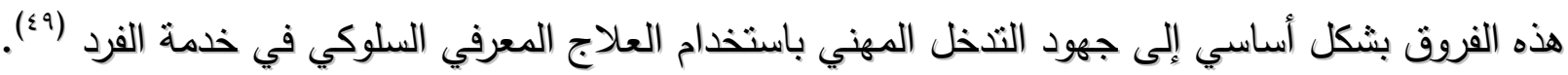

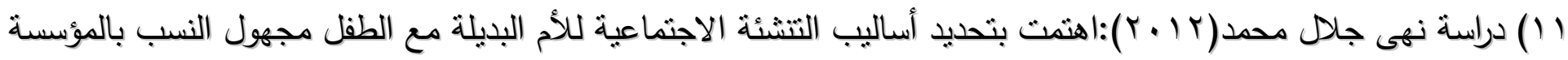

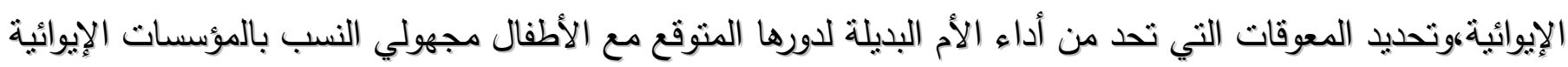

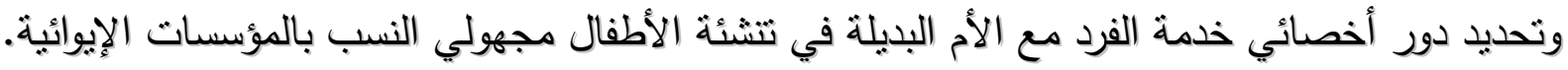

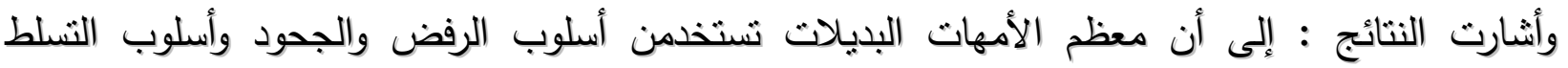

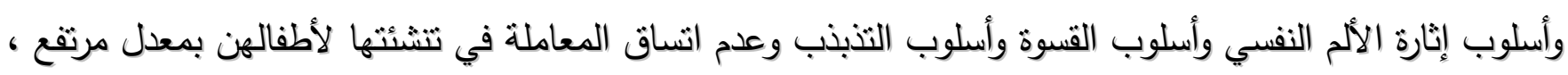
كما تستخدم بعض الأمهات البديلات أسلوب التقبل والديمقراطية واتساق المعاملة والتدليل والحماية الزائدة والإهمال

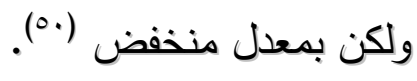

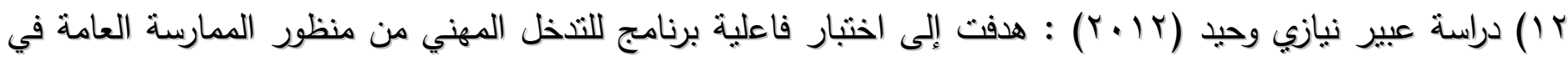

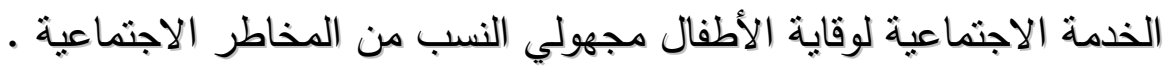

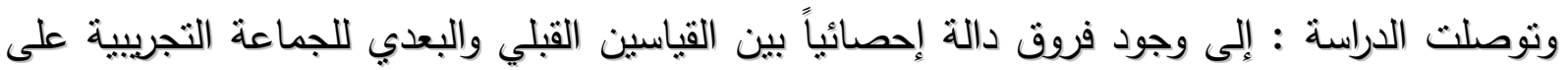

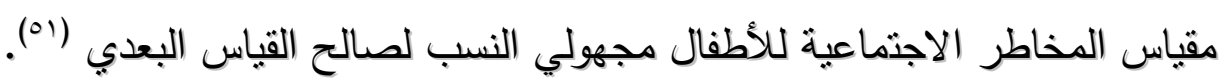
وباستقراء نتائج الدراسات السابقة نجد أن : 


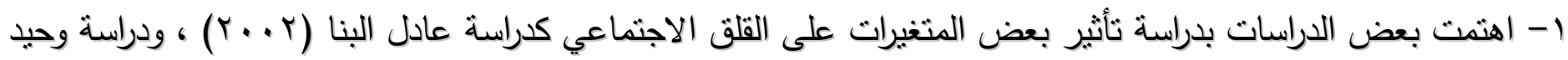

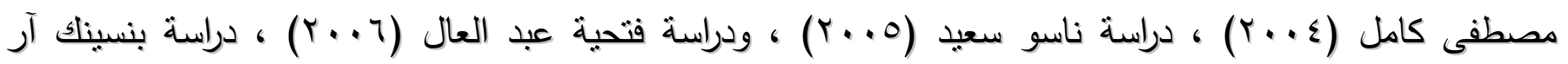
Bensink, R,

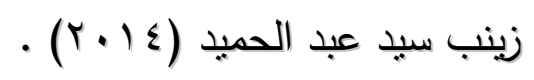

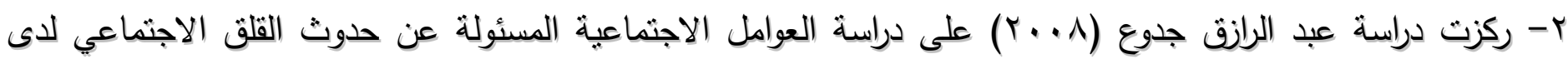

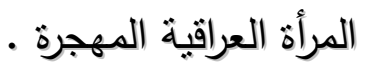
r- اهتمت بعض الدراسات بالتدخل للتخفيف من حدة القلق لبعض الفئات كالمكفوفين ، والثباب الجامعي .

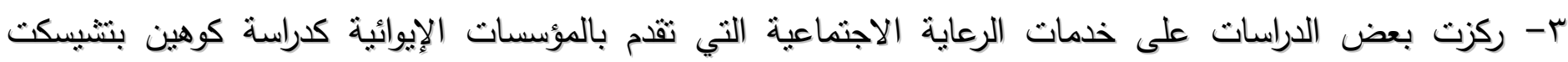
Cohen Yecheskiet ع- اهنت بعض الدراسات بدراسة تأثثر الحرمان من الحياة الأسرية على شخصية وسلوك الأطفال كدراسة ولف

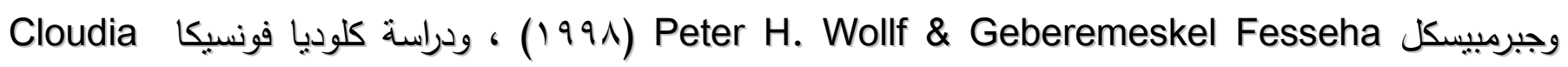
• (r...r) Fonseca 0- ركزت بعض الدراسات بالتدخل المهني للتخفيف من حدة بعض مشكلات مجهولي النسب كدراسة هناء أحمد أمين

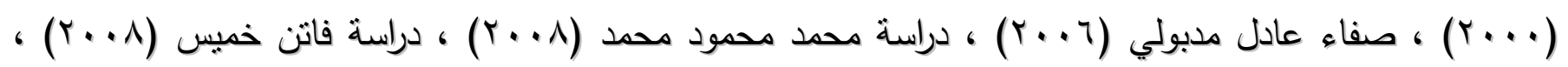

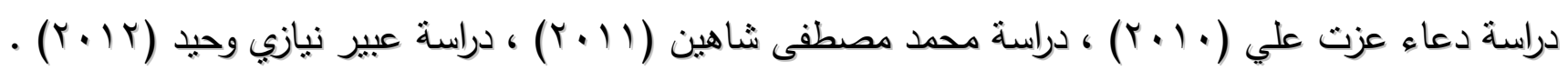

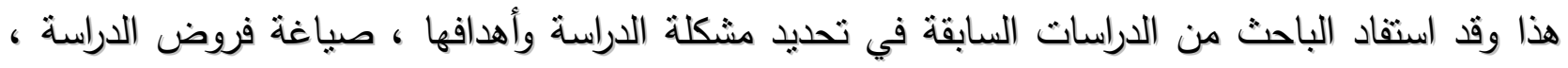

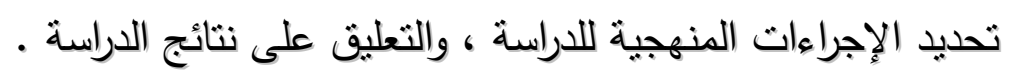

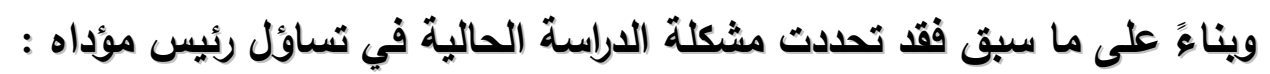

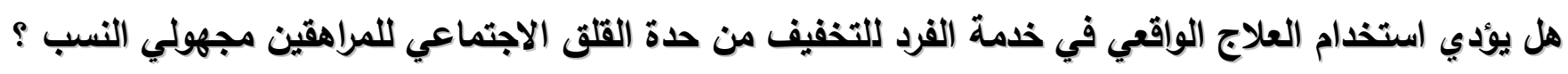
ثانياً : أهمية الدراسة : الهوب 1 - يعثبر دراسة القلق الاجتماعي أمراً هاماً لأنه أحد المشكلات التي تعوق الفرد عن التقدم في الحالات الحياتية ، وما يمكن

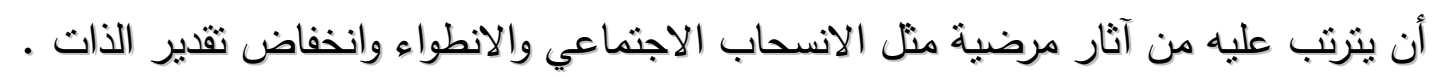

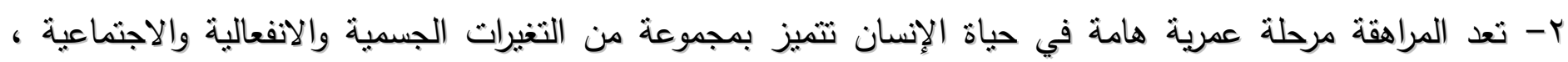

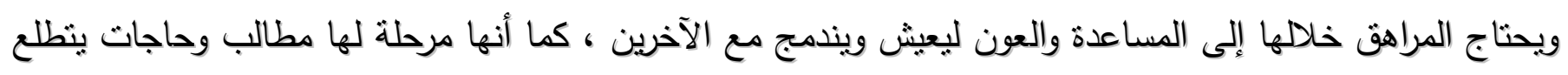

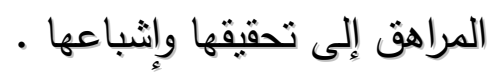
r- ما أثشارت إليه نتائج الدراسات السابقة من أن المراهقين المودعين بالمؤسسات الإيوائية يعانون من العديد من المشكلات

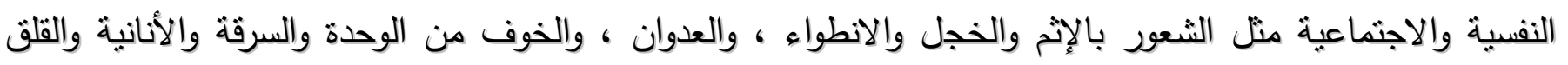

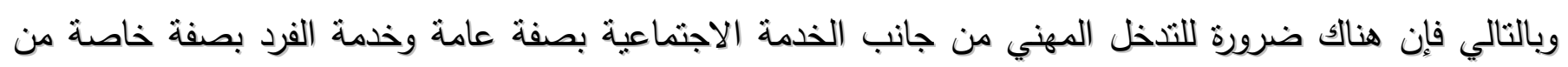

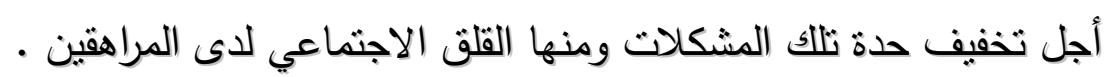

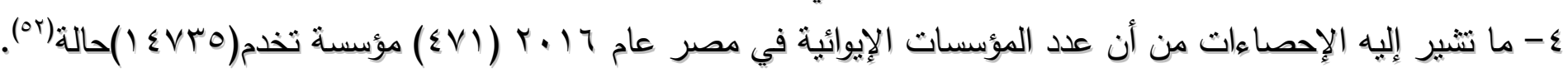

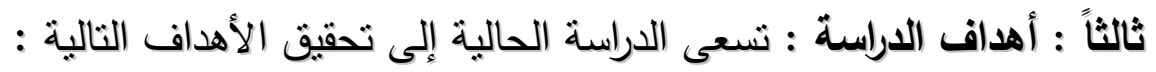


1- تصميم برنامج للتنخل المهني من منظور العلاج الواقعي في خدمة الفرد بهدف التخفيف من حدة القلق الاجتماعي

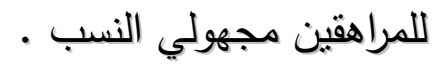

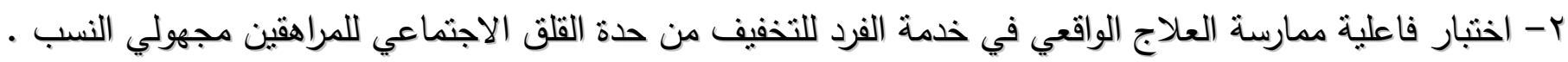

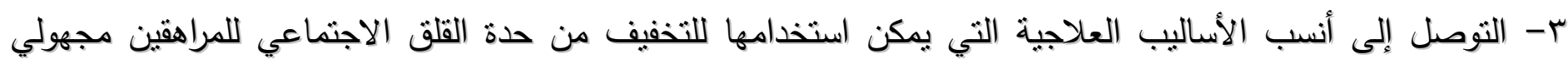

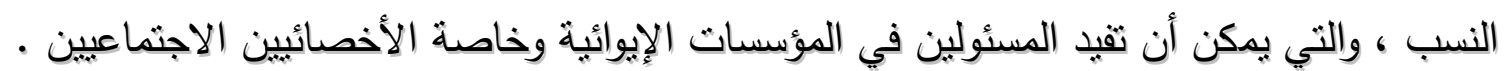
رابعاً : فروض الاراسة : الفرض الفرض الرئيسي : نوجد علاقة ايجابية ذات دلالة إحصائية بين ممارسة العلاج الواقعي في خدمة الفرد والتخفيف من حدة

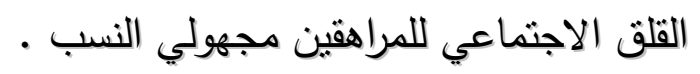

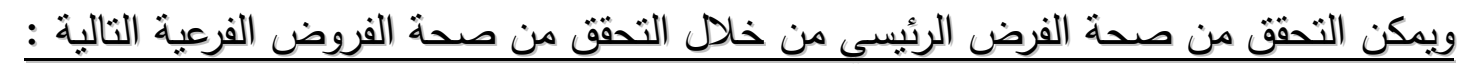
أ- توجد علاقة ايجابية ذات دلالة إحصائية بين ممارسة العلاج الواقعي في خدمة الفرد والتخفيف من حدة الاضطرابيات

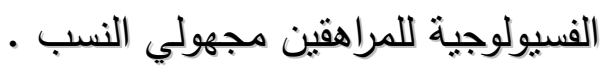
ب- نوجد علاقة ايجابية ذات دلالة إحصائية بين ممارسة العلاج الواقعي في خدمة الفرد والتخفيف من حدة ضعف الثقة في

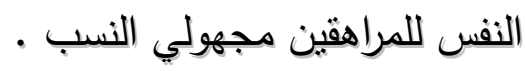
ج- توجد علاقة ايجابية ذات دلالة إحصائية بين ممارسة العلاج الواقعي في خدمة الفرد والتخفيف من حدة صعوبة التواصل والتعبير عن النفس اللمراهقين مجهولي النسب .

خامساً : مفاهيم الدراسة :

1- مفهوم العلاج الواقعي : تعثبر المدرسة الواقعية أحدث الددارس العلاجية الرافضة للمنظور التحليلي ، ويراها كثيرون أنها

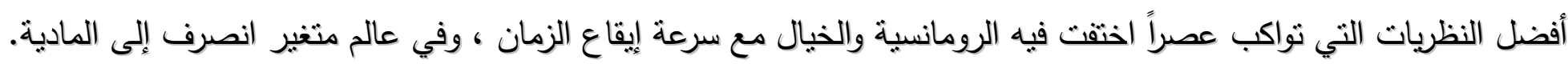

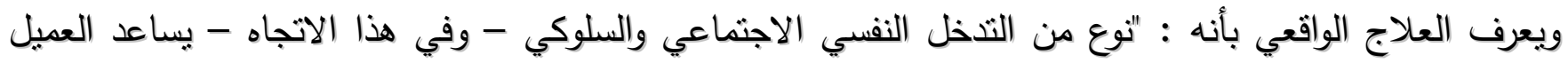
على تتمية ذاتية ناجحة مبنية على الحب والقيمة " . كما يعرف بأنه : " مدخل قصير لعلاج اضطرابات الثخصية من خلال المواجهة الدافئة بالواقع باعثباره حقيقة

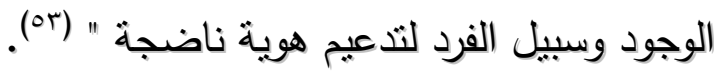
كما يعرف بأنه : " أسلوباً ومدخلاً علاجياً من خلال إعطاء العملاء أفضل اهتمام بحياتهم ومساعدتهم على تحقيق

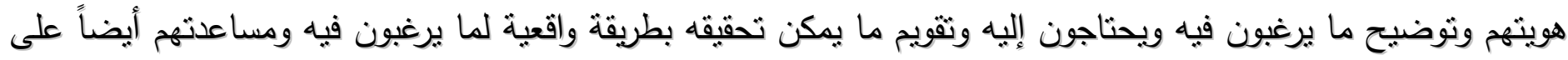

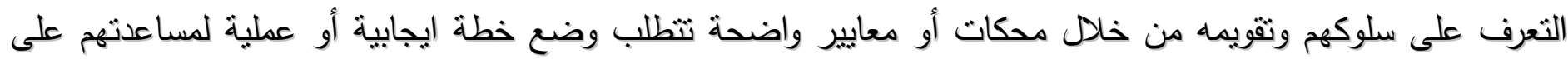

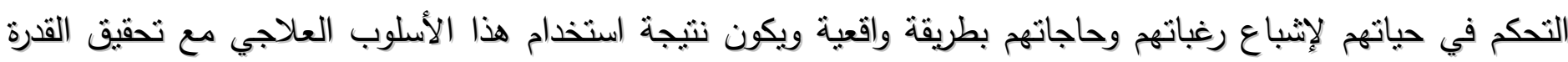

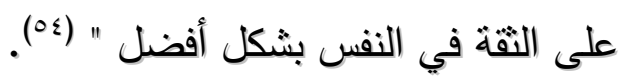

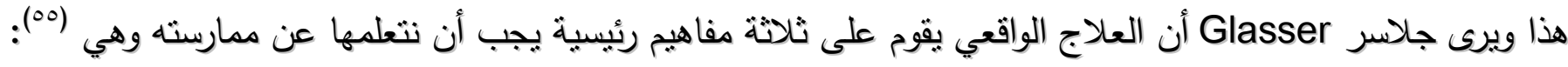

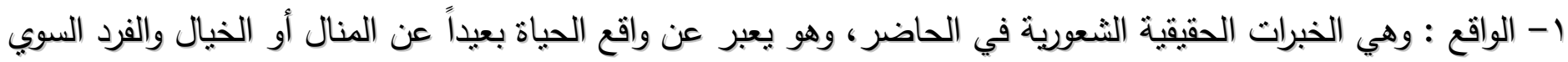

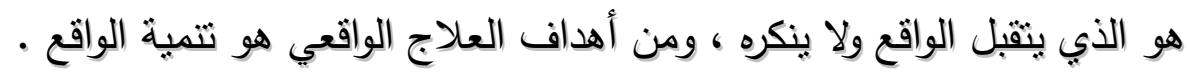


r- المسئولية : وتتجلي في قدرة الفرد على إثباع حاجاته وتحقيق ما يشعره بقيمة ذاته (في نظره - وفي نظر الآخرين)

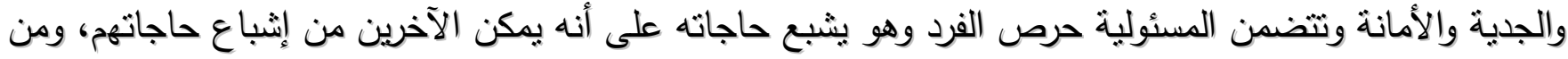

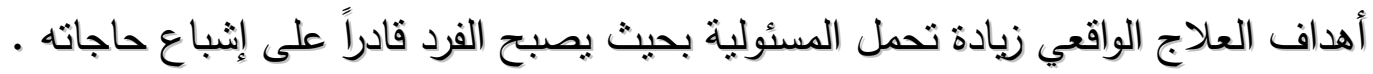

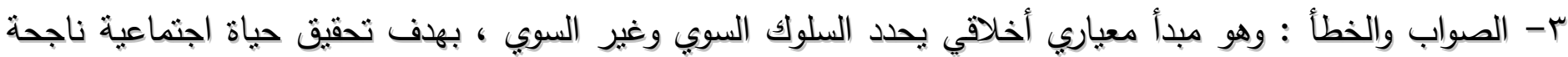

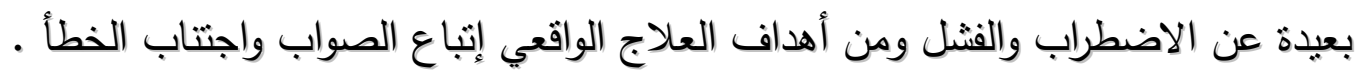

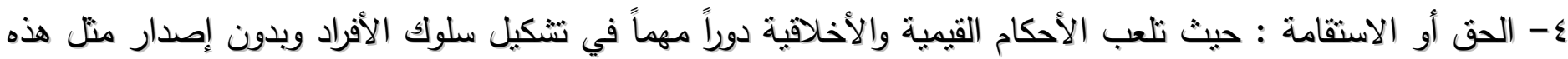

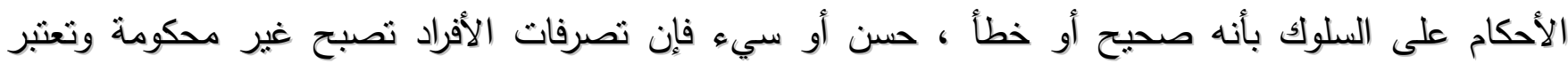

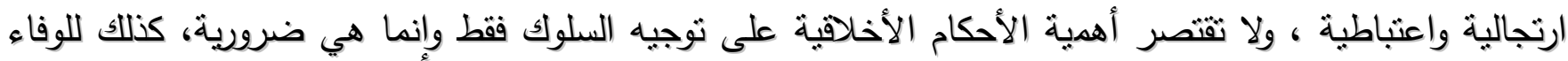

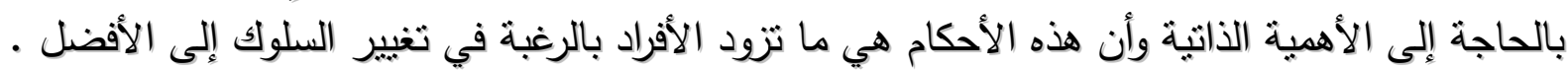

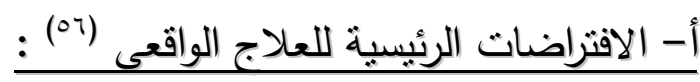

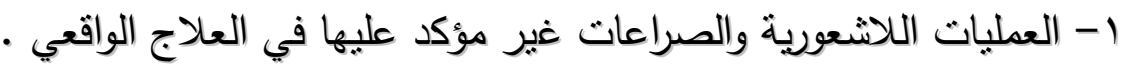

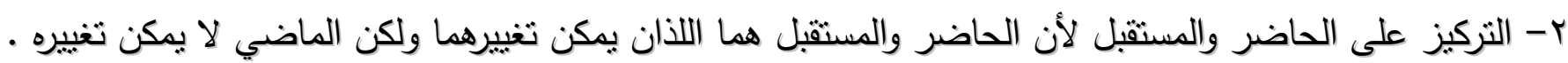

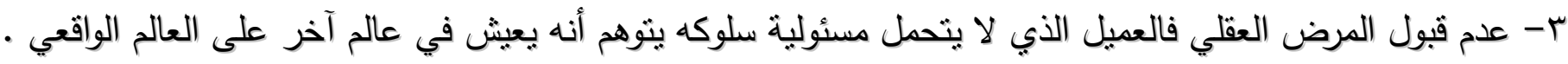

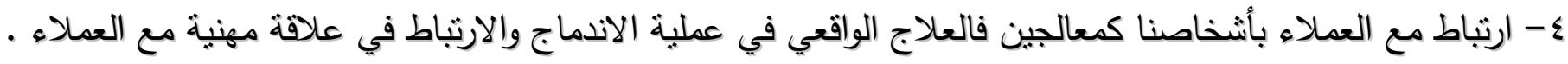

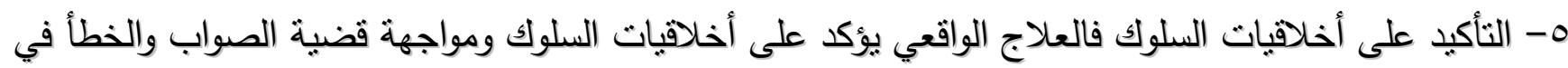

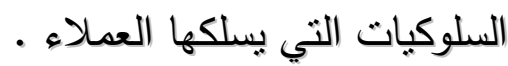

1- تعلم طرق محسنة للسلوك فالعلاج الواقعي يركز على تعليم العملاء أفضل الطرق لإتباع حاجاتهم الأساسية واكتساب

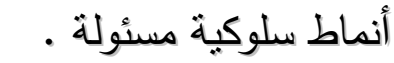

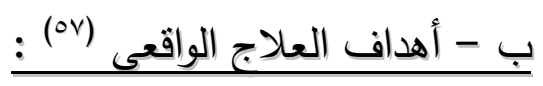

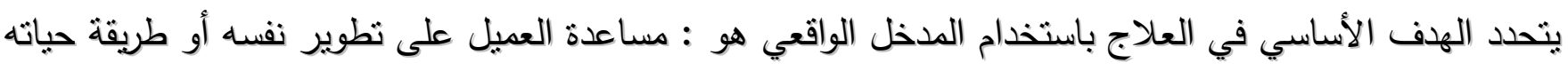

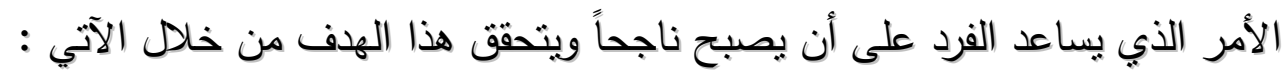

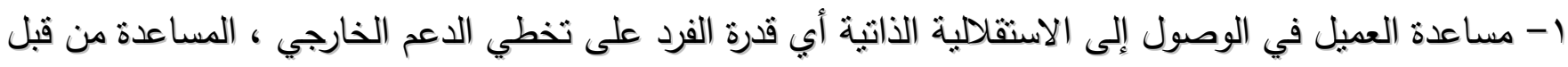

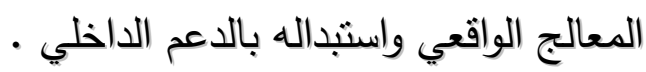

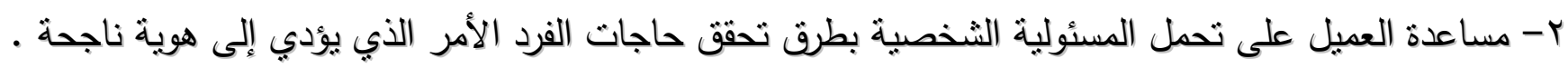

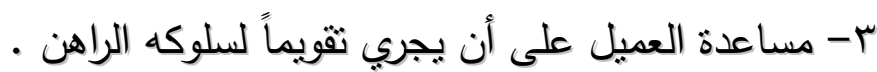

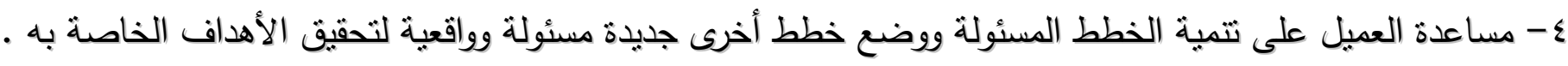

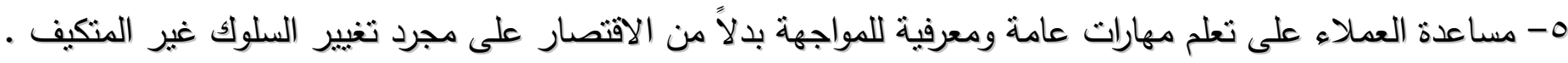

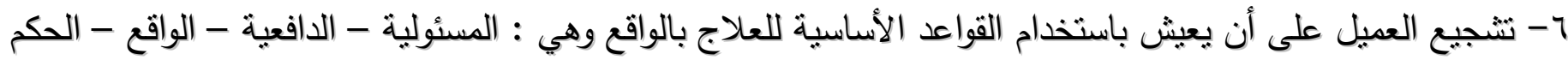

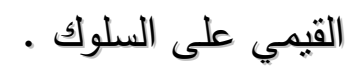

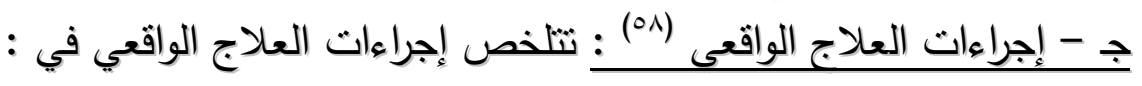

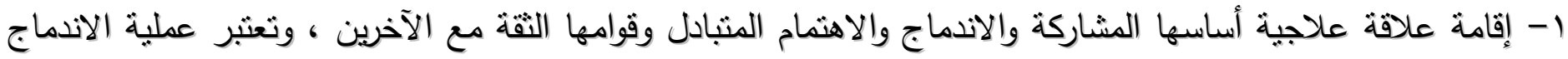
هي المهارة الرئيسية في العلاج الواقعي . 
r- دراسة السلوك الحالي في ضوء إدراك الواقع ورفض السلوك غير الواقعي والاعتراف بالواقع والتعامل معه ، في إطار

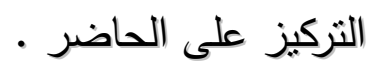

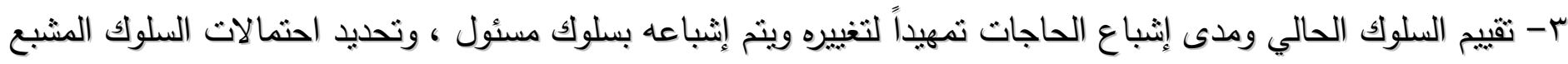

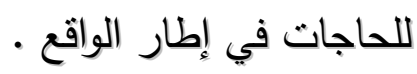
ع - اختيار وتقرير السلوك المشبع للحاجات والمحقق للهذف بصورة ناجحة ، وهذا يعتبر بمثابة نعاقد علاجي لعمل ما هو

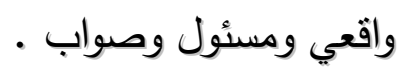

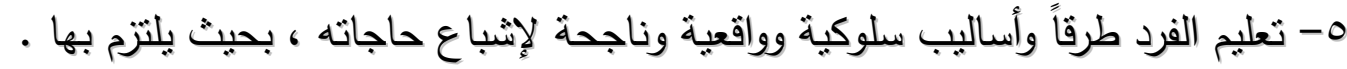

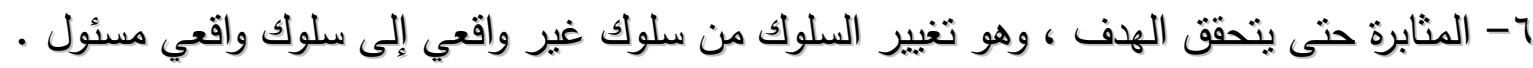
r- مفهوم القلق الاجتماعي :

يعرف القلق بصفة عامة بأنه : " حالة نؤثر ثأثثر شامل ومستمر نتيجة لتهديد خطر فعلي أو رمزي قد يحدث

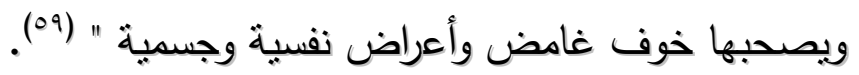

كما يعرف بأنه : "خوف مزمن دون مبرر موضوعي مع نوافر أعراض نفسية وجسمية شتى دائمة إلى حد كبير"(·").

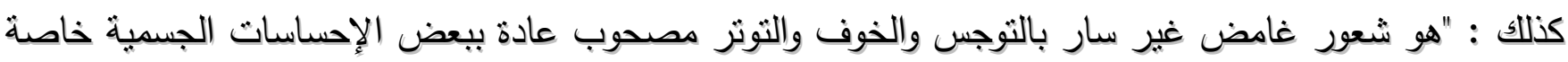

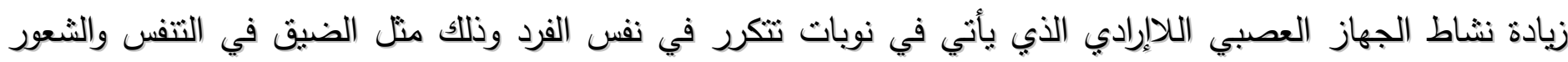

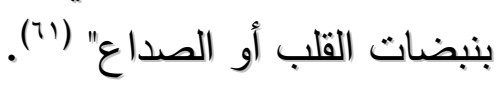
أما عن القلق الاجتماعي فيعرف بأنه : " هو وصف لحالة مرضية تتكون من شعور بالقلق والتوتر في المناسبات

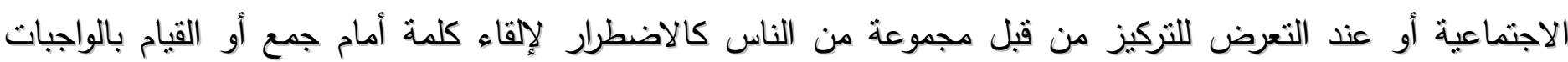

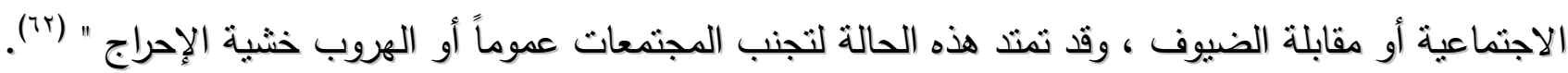

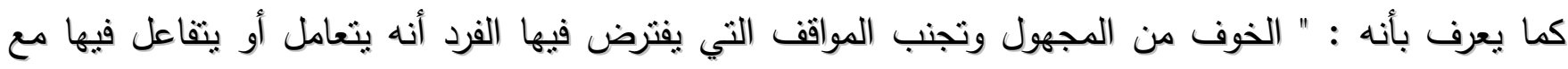

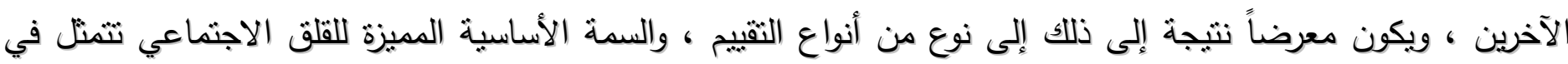

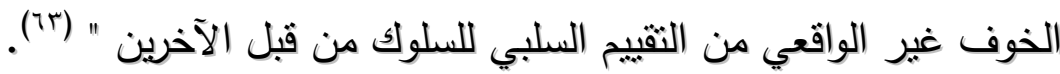

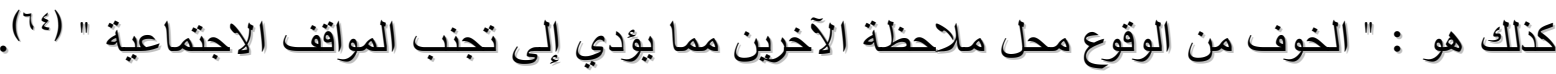

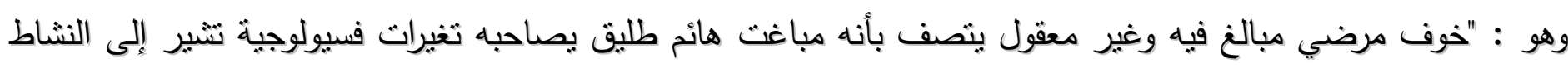

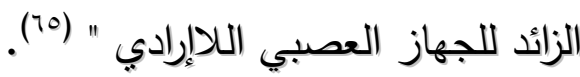
أ- مظاهر القلق الاجتماعى : للقلق الاجتماعي عدة مظاهر تختلف من شخص لآخر حسب أساليب التشئئة واستعداداته

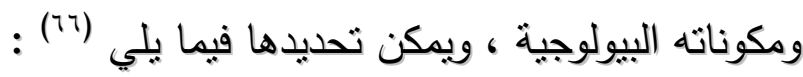

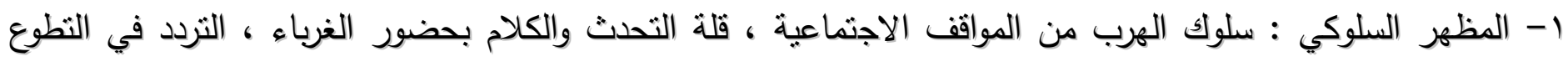

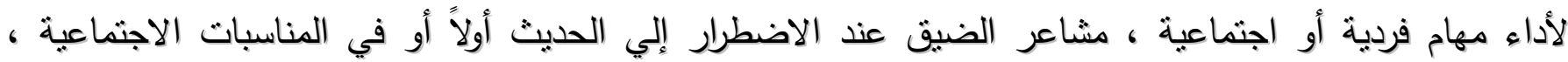

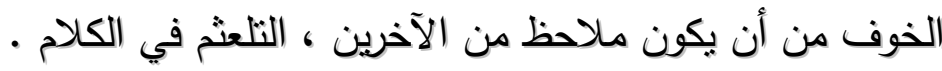


r- مظهر فسيولوجي: ويتجلى في أعراض جسدية نتمثل في: زيادة النبض، زيادة دفات القلب، مشـاكل في المعدة (كسوء

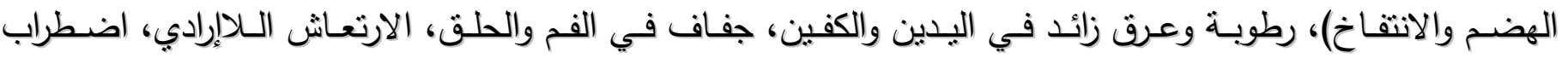

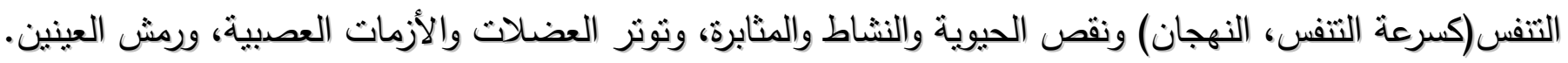

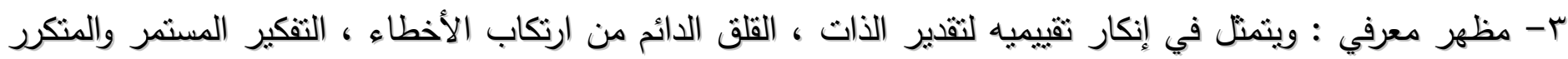
للمواقف الاجثماعية المثيرة للقلق وما يعتقده الآخرون عنه ، امتلاك خيال سلبي ، الانتباه الزائد من قبل الفرد بنفسه . ب ب - المكونات الأساسية للقلق الاجتماعى (TV) 1- مكون فسيولوجي : ويشير هذا المكون إلى ظهور بعض الأنس الأعراض الفسيولوجية على الأفراد ذوي القلق الاجنماعي ،

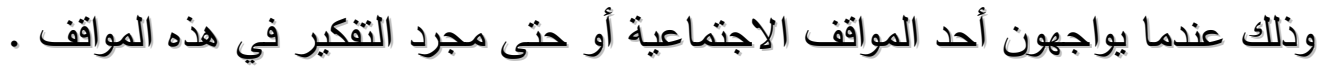

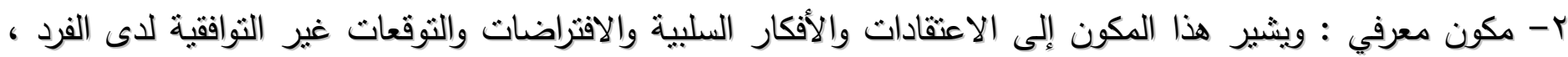

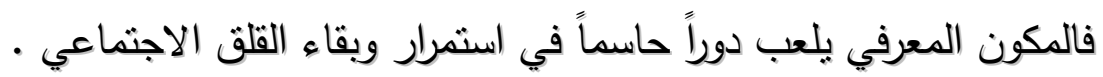

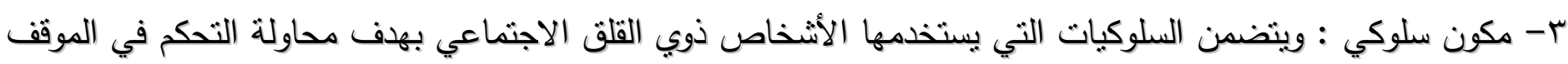
وخفض مستوى القلق لديهر .

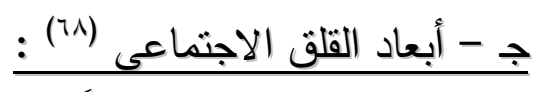

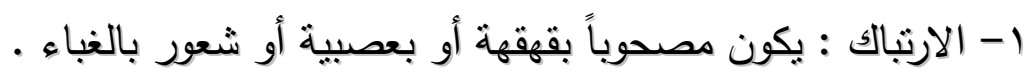

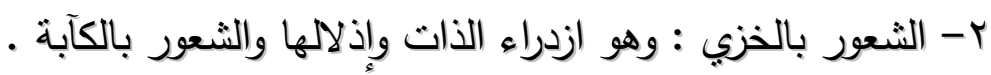

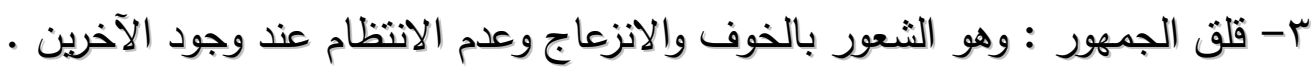

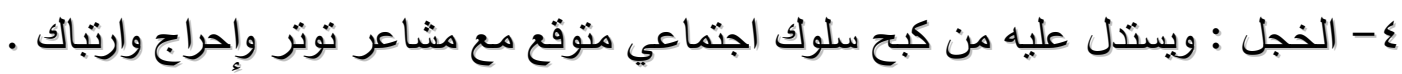

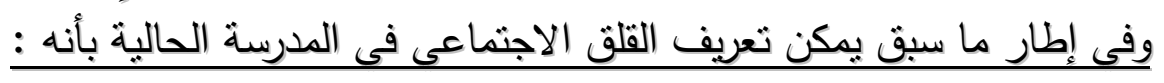

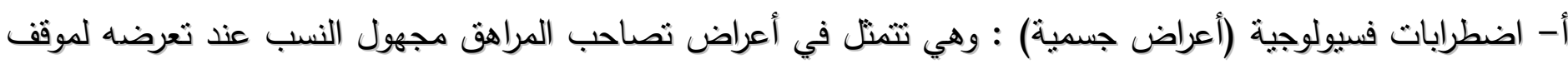

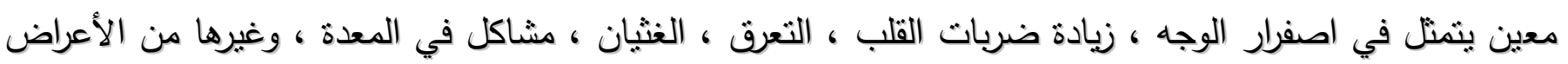

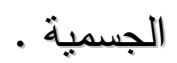

ب- ضعف الثقة بالنفس : ويتمثل في الثعور بالسلبية والتردد وضعف الثقة التي تجعل المراهق مجهول النسب بتصرف

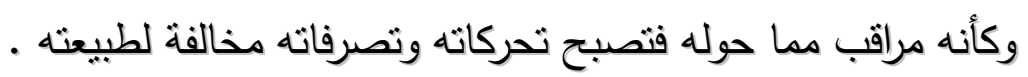

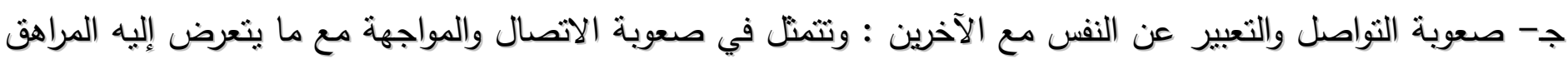

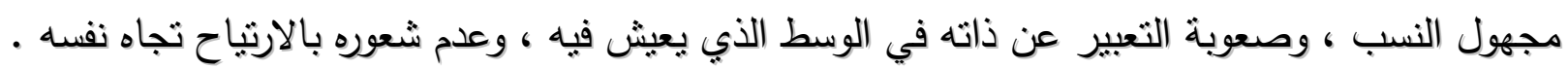

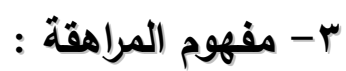

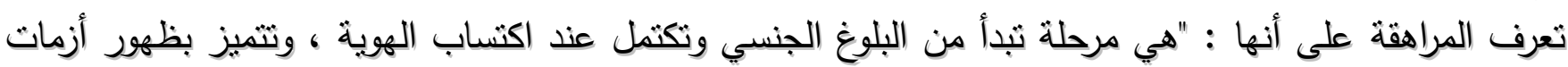

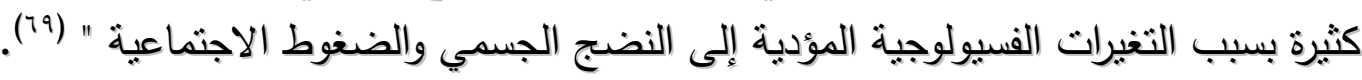

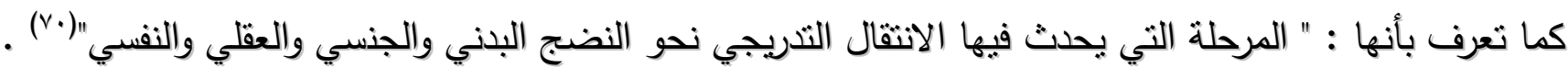

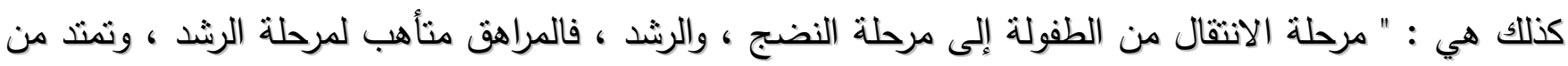

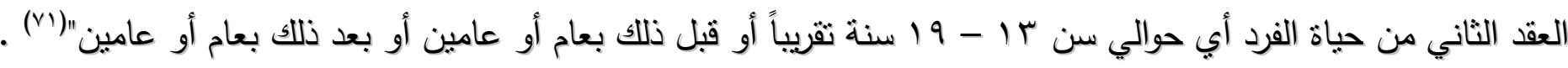


وتعرف أيضاً بأنها : " المرحلة الثي يعبرها الطفل كي ينتقل من مرحلة الطفولة إلى مرحلة الرشد ، وتمثن هذه المرحلة

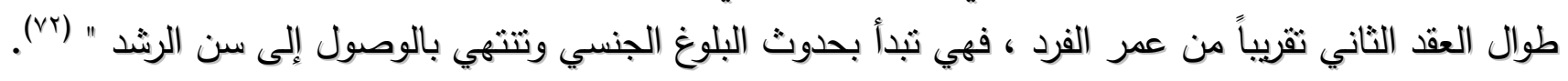

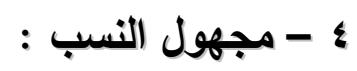
هناك العديد من المفاهيم التي تناولت مجهول النسب فهناك من بطلق عليه (اللقيط) ، والطفل غير الثرعي هو

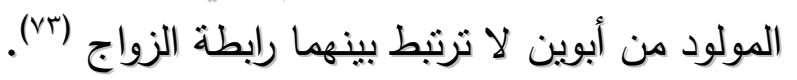

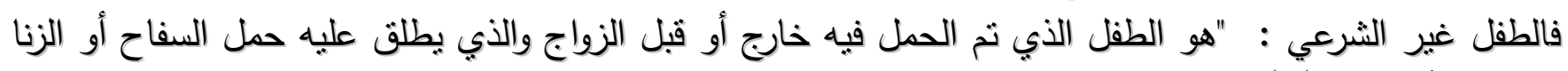

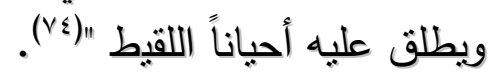
واللقيط هو : " كل طفل حديث الولادة بعثر عليه والغالب أن يكون نبذه أهله فراراً من عار الزنا ، ولكن لا يشترط أن

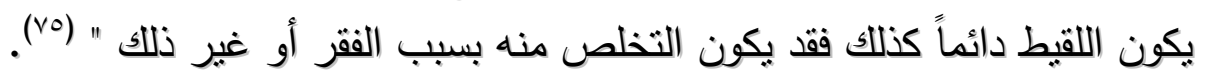

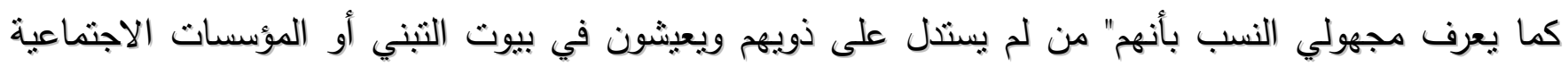

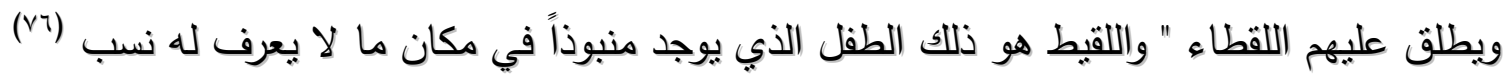

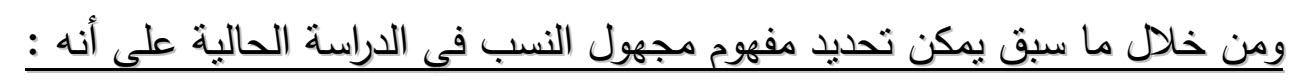

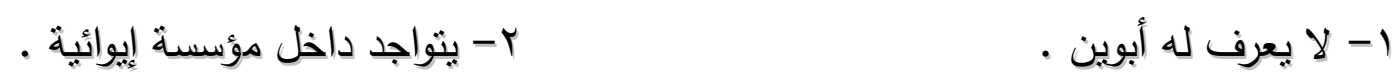

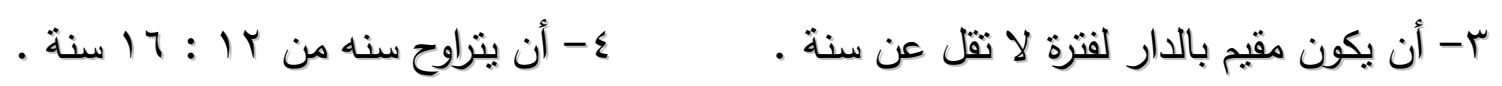

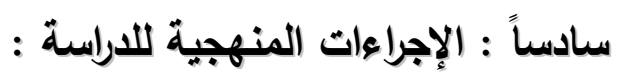

( ) نوع الدراسة والمنهج المستخدم : تمشياً مع أهداف الدراسة فإن الدراسة الحالية تنتمي إلى نمط الدراسات شبه التجريبية

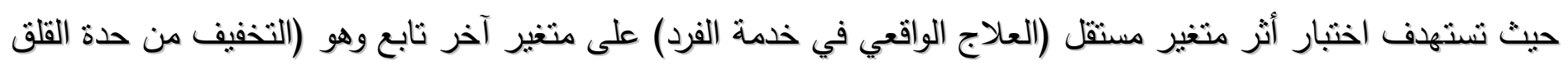

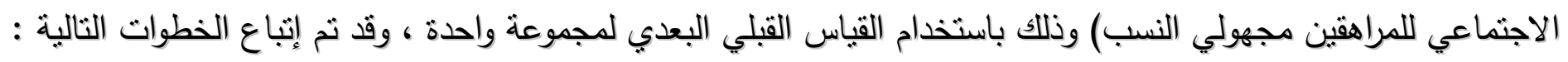

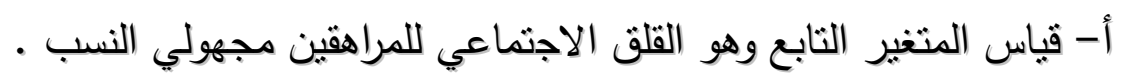

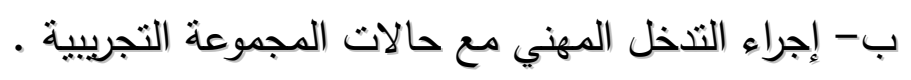

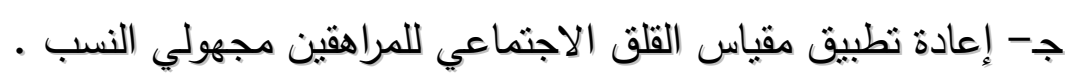

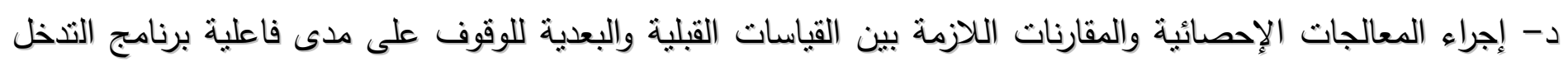

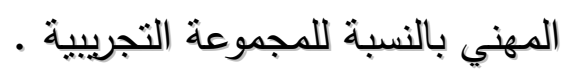

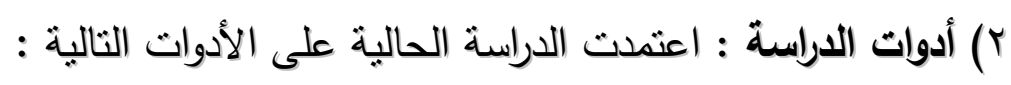

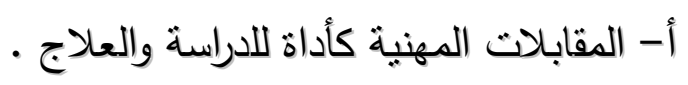

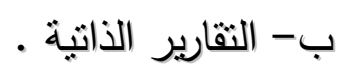
ج- مقياس القلق الاجنماعي للمراهقين مجهولي النسب(وهو من إعداد الباحث)،وقد تم إتباع الخطوات التالية في إعداد المقياس: 1- تحديد موضوع القياس : وذلك في ضوء المتغير التابع الذي من خلاله التعرف على مدى التغيير فيه ، ويتمنل في القلق

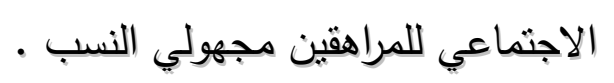

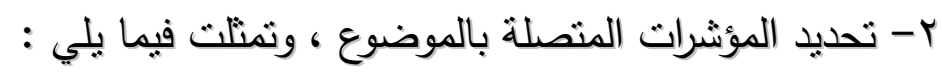

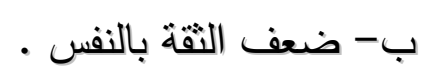
أ- الاضطرابات الفسيولوجية . 
ج- صعوبة التواصل والتعبير عن النفس .

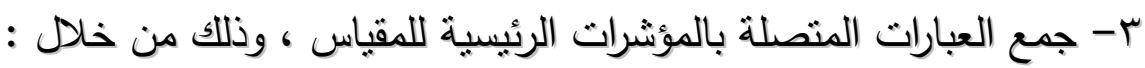

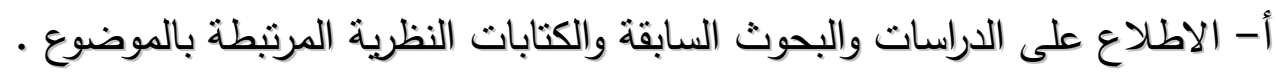

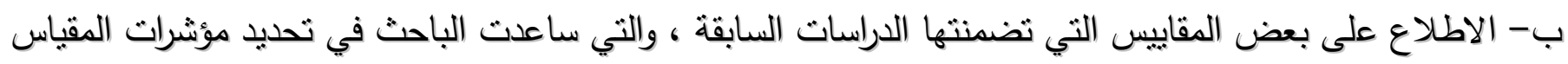

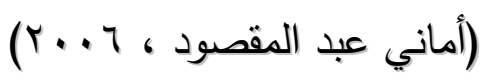

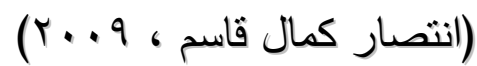

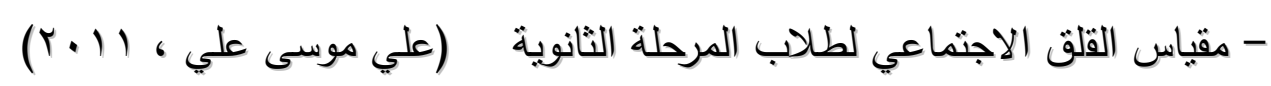

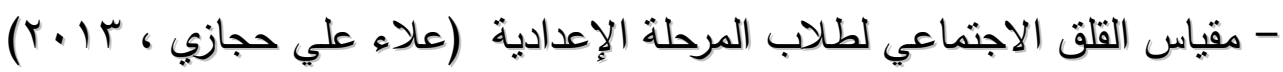

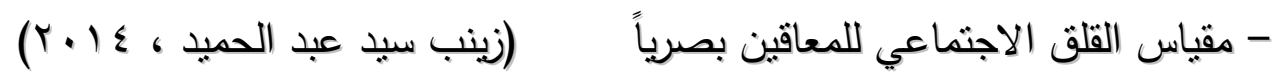

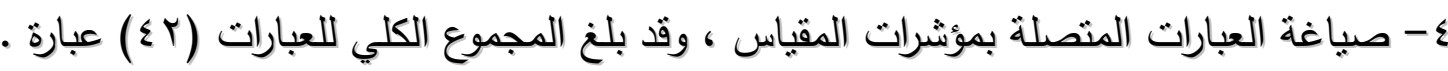

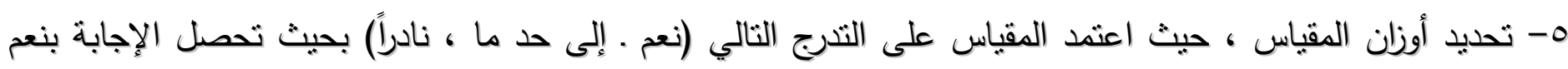

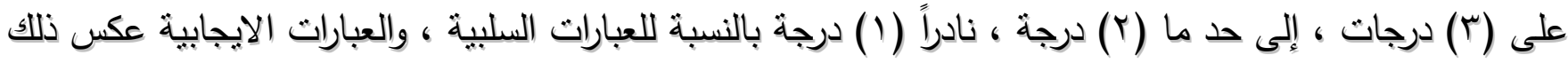

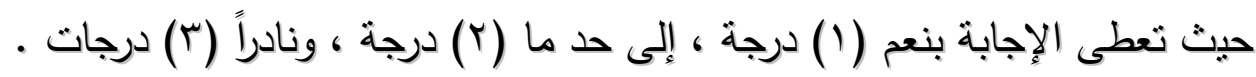

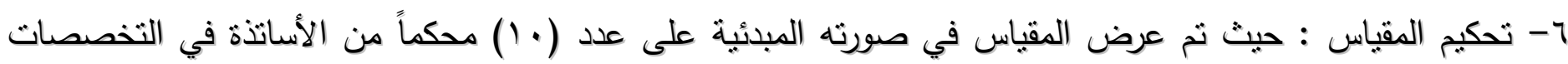

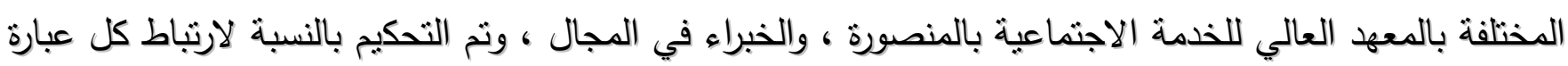

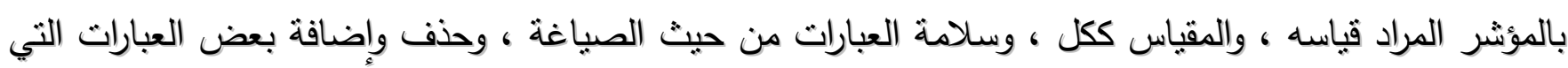

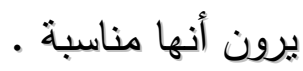

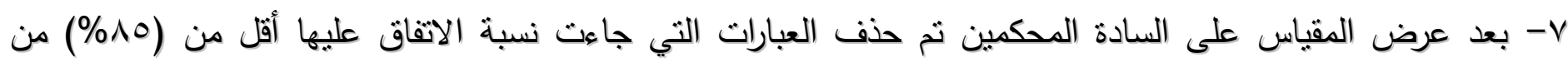

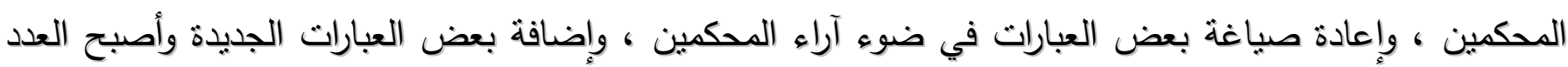

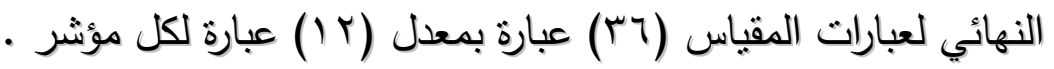
1- مرحلة التأكد من ثبات وصدق المقياس : أ- ثبات المقياس : حيث نم استخدام طريقة إعادة الاختبار بتطبيق المقياس على القياس في صورته المبدئية على (·ـ (1)

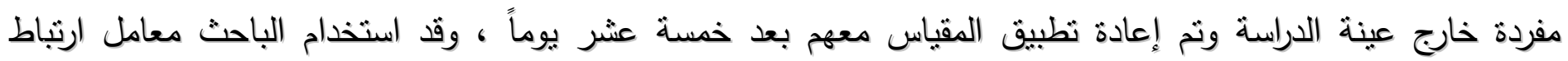

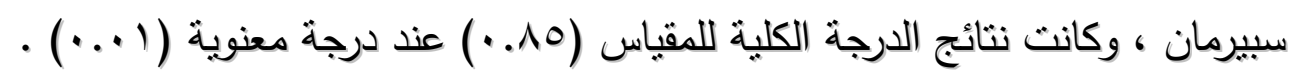

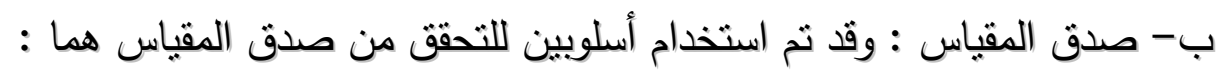
(1) الصدق الظاهري : حيث ثم عرض المقياس على عدد من المكمين من أساتذة المعهد لعالي للخدمة الاجتماعية

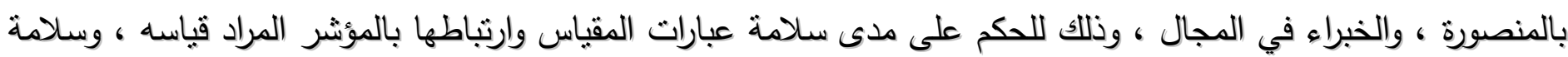

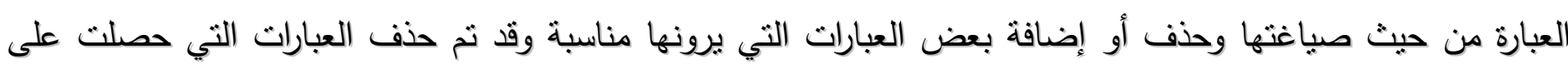

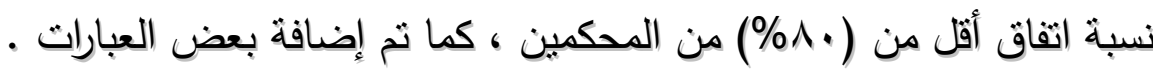

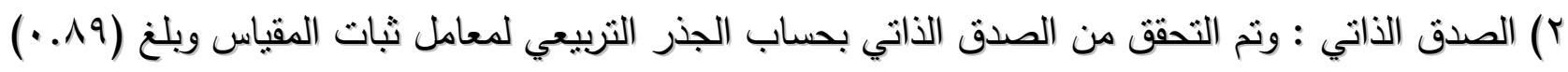


وفيما يلي جدول يوضح معامل الثبات والصدق الذاتي على مؤشرات المقياس ، والمقياس ككل .

$$
\text { جدول رقم (1) }
$$

\begin{tabular}{|c|c|c|c|}
\hline 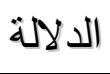 & 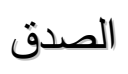 & 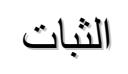 & مؤشرات المقياس \\
\hline \multirow{4}{*}{$\cdots+1$} &..$\wedge \vee$ & $\therefore$ Vr & الاضطرابات الفسيولوجية \\
\hline & $\because .91$ &.$\wedge r$ & ضعف الثقة في النفس \\
\hline & $\because 9$ &..$\wedge r$ & صعوبة التدخل والتعبير عن النفس مع الآخرين \\
\hline &. .19 & $\therefore \wedge$. & المقياس ككل \\
\hline
\end{tabular}

ب- مجالات الدراسة :

أ- المجال المكانيى : تحدد المجال المكاني في مؤسسة تربية البنين بالمنصورة ، وذلك للأسباب الثالية :

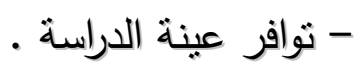

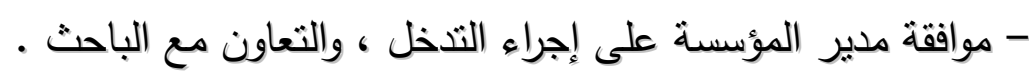

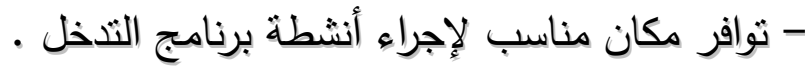

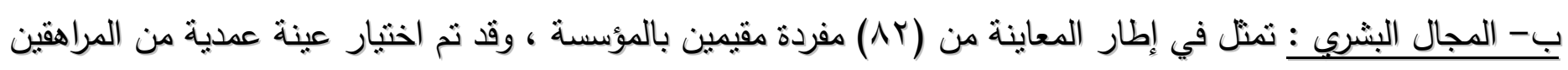

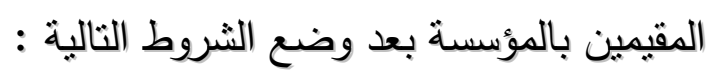

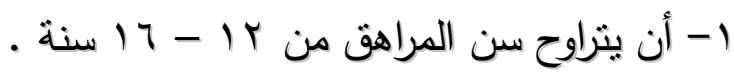

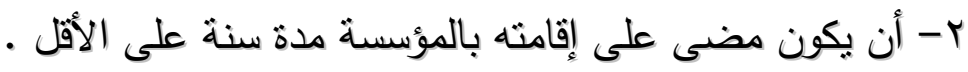

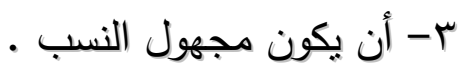

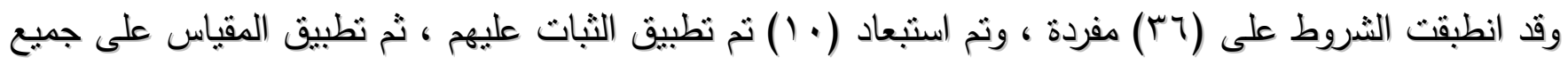

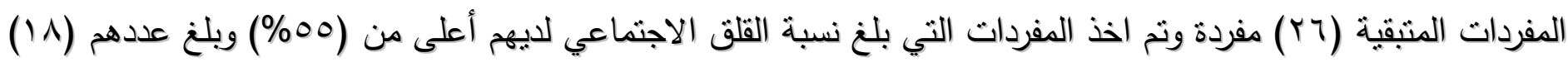

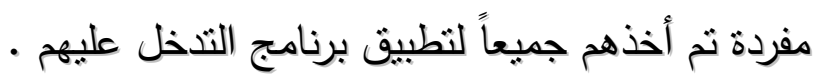

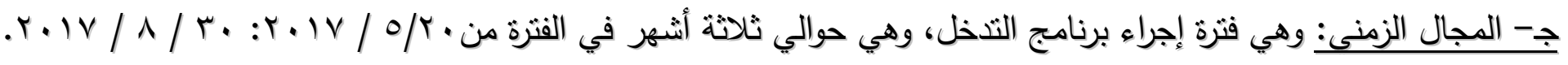

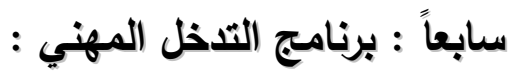

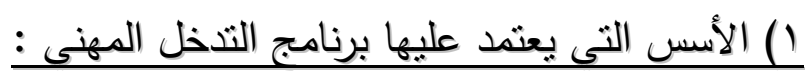

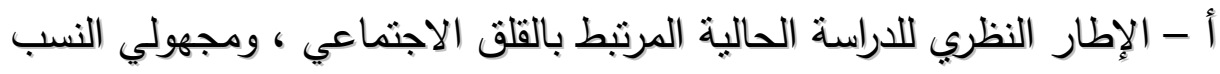

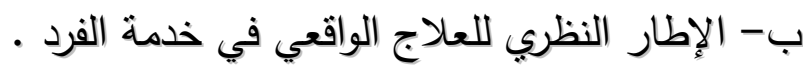

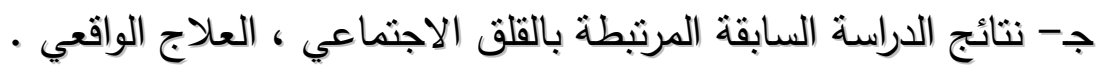

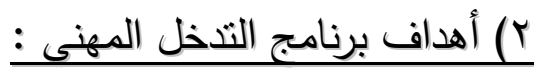
الهدف الرئيسي : التخفيف من حدة القلق الاجنماعي للمراهقين مجهولي النسب .

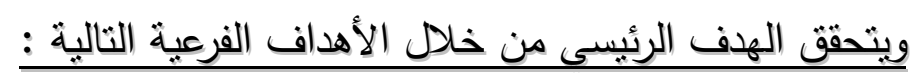

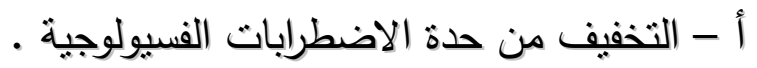


ب- التخفيف من حدة ضعف الثقة بالنفس .

ج- التخفيف من حدة صعوبة النواصل والتعبير عن النفس أمام الآخرين .

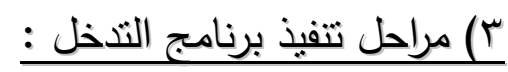

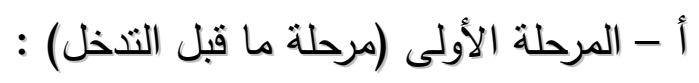

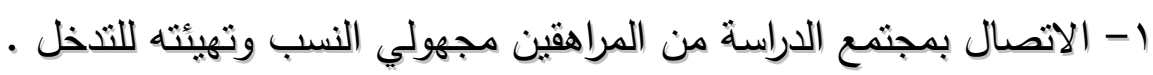

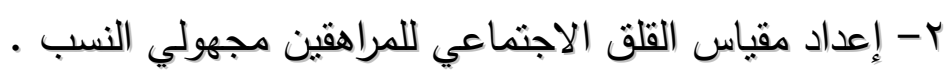

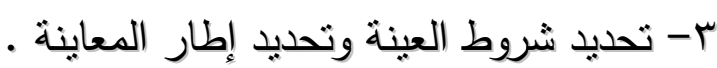

ع - تطبيق مقياس القلق الاجتماعي للمراهقين مجهولي النسب على المعاينة أفراد العينة .

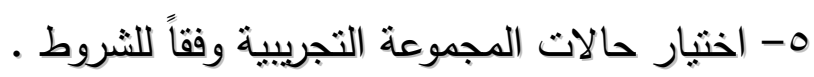

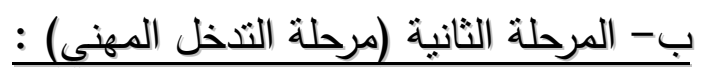

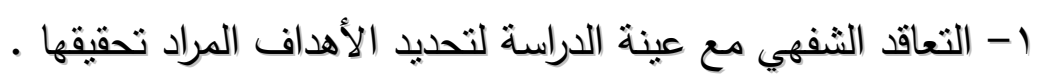

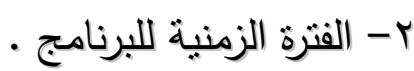

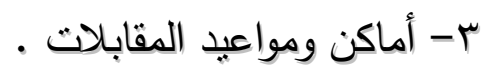

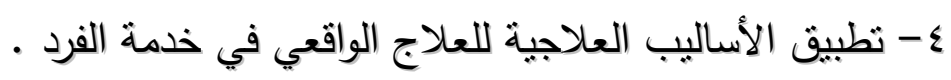

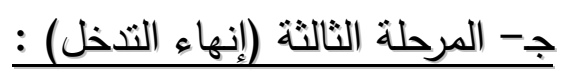

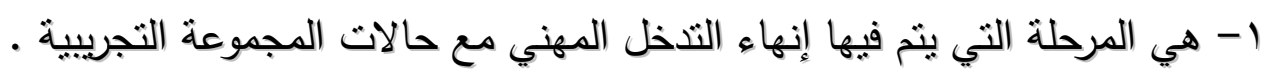

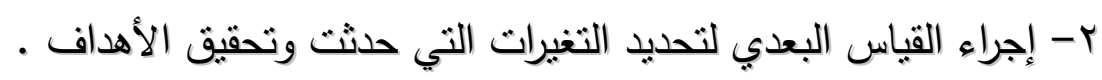

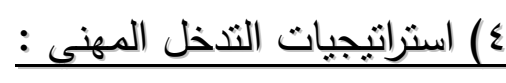

أ - الحديث إلى الذات : وذلك من خلال مساعدة المراهقين مجهولي النسب على معرفة حديث الذات السلبي والذي بعثبر

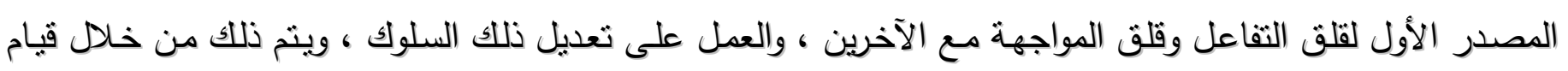

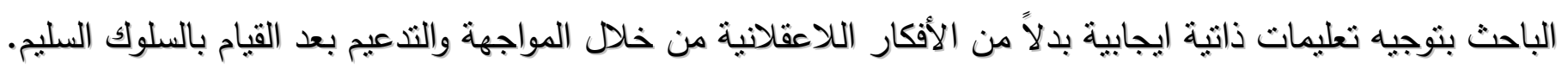

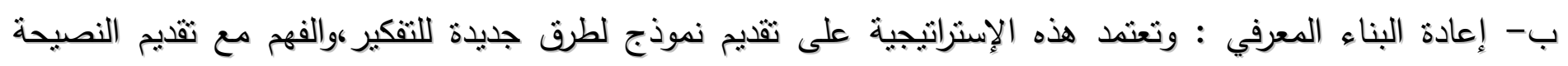

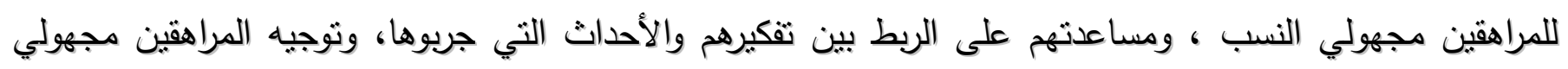

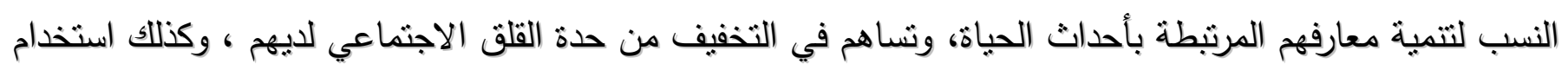

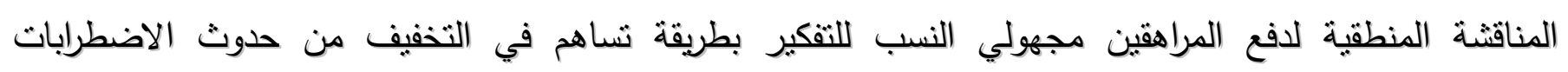
الفسيولوجية ، وضعف ثقتهم في نفسهر ، وتتمي قدرتهم على التواصل مع الآخرين ، وقدرتهم على التعبير عن أنفسهر.

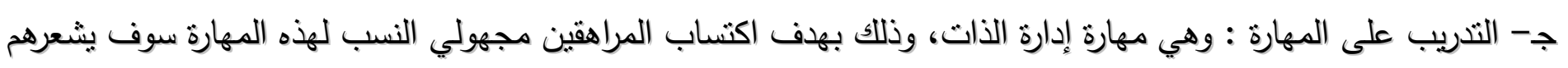

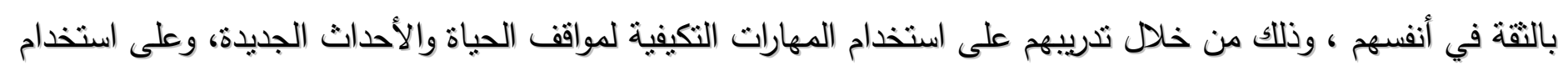
مهارات المواجهة، وذلك من أجل مواجهة صعوبة التواصل والتعبير عن النفس أمام الآخرين،وزيادة نقتهم في أنفسهم. 
د- الواجبات المنزلية المعرفية : حيث يقام الباحث للمراهقين مجهولي النسب واجبات معرفية منزلية تنثتل في قيام المراهقين

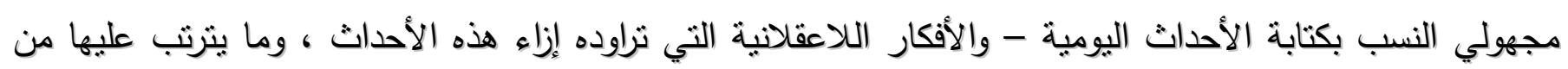

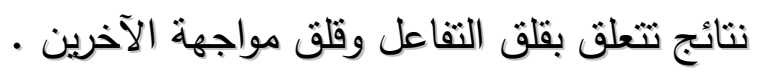

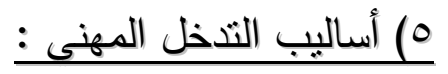

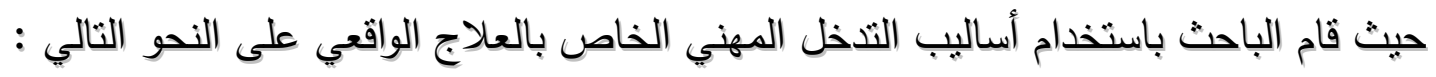

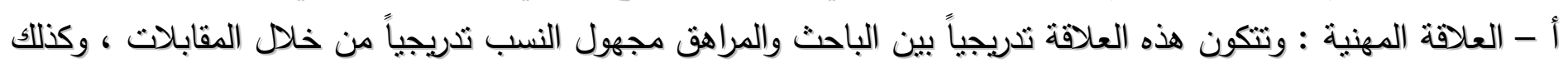

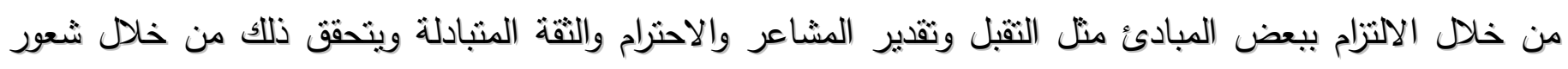

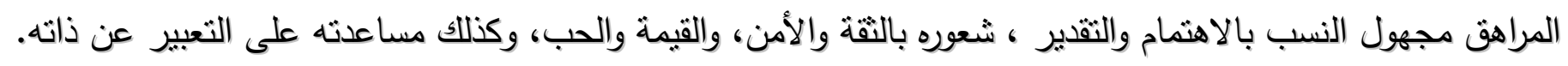

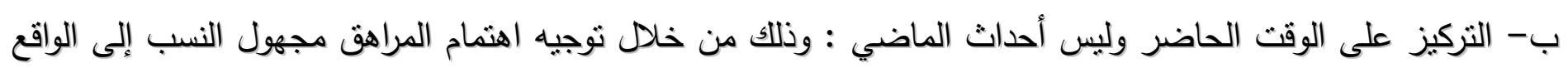

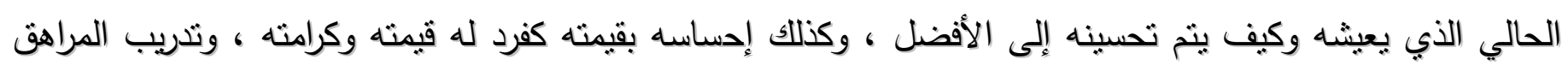

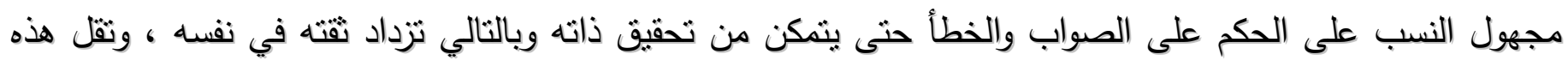

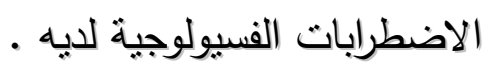

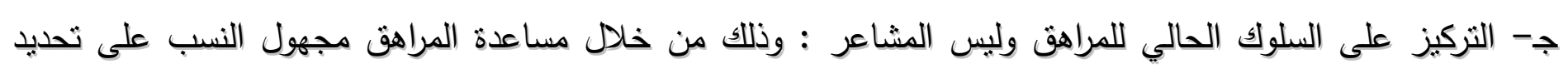

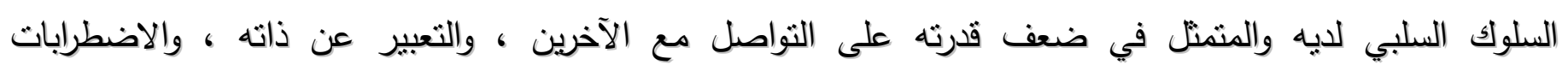

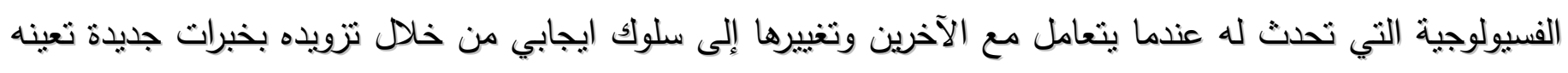

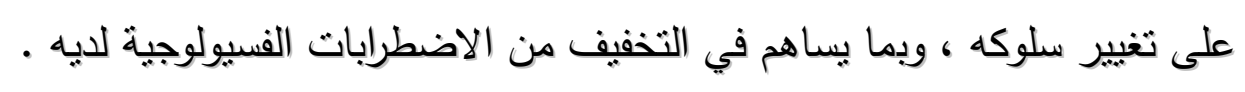

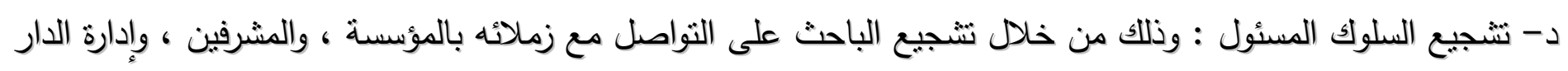

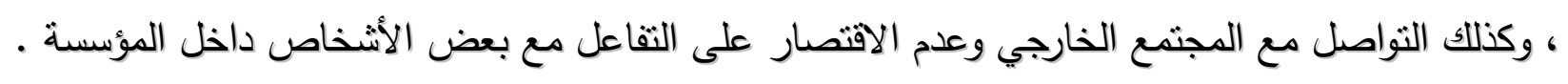

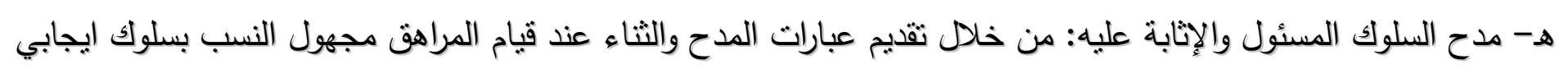

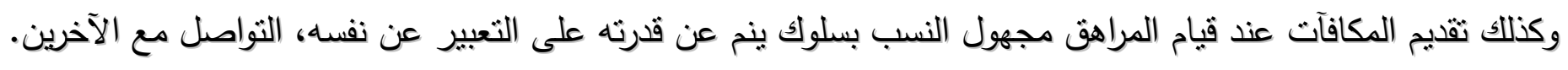

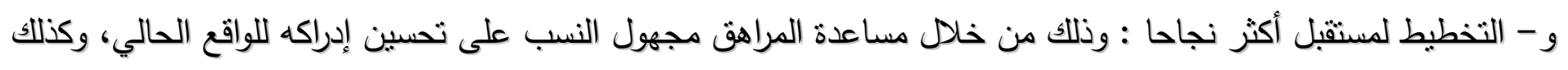

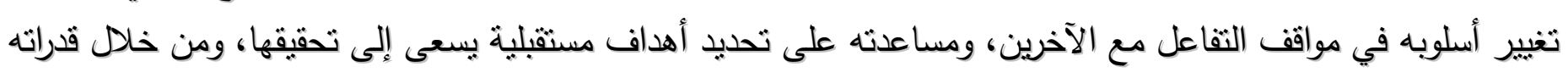

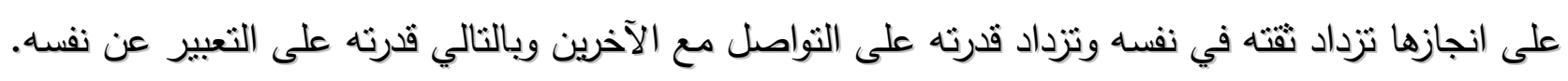

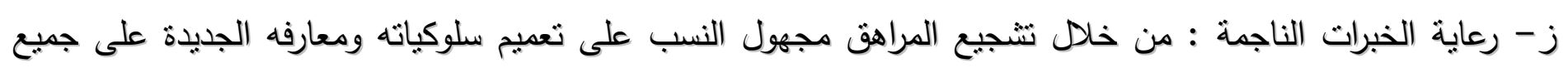

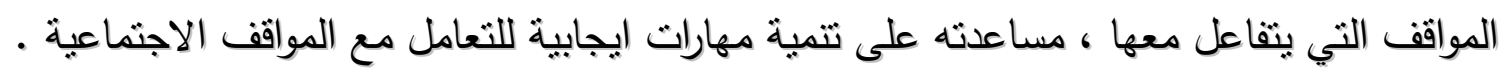

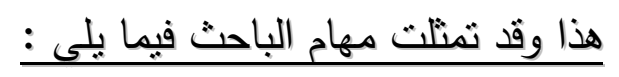

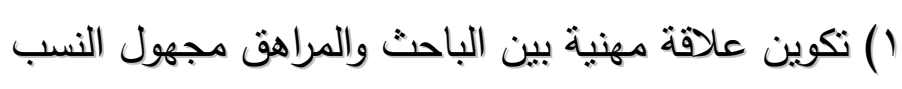

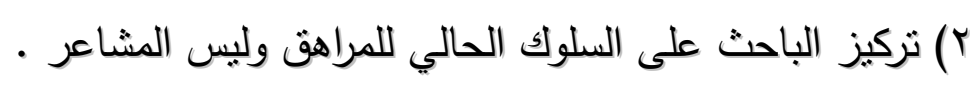

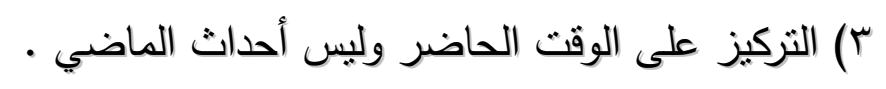

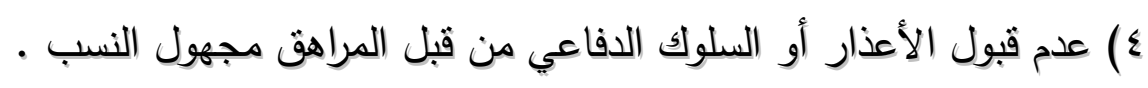
0) تثجيع المراهق مجهول النسب للنحرك نحو النخفيف من حدة القلق الاجنماعي بصورة استقالالية . 
7) التركز على ما يجب عمله حالياً والابتعاد عن مناقثة المبررات والأسباب .

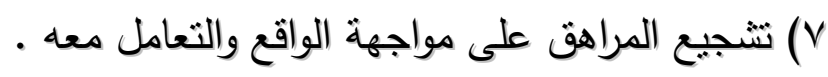

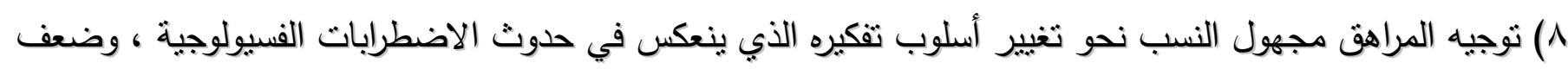

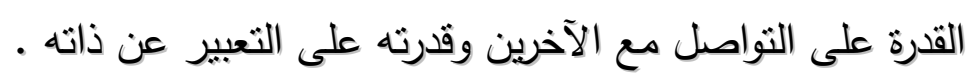

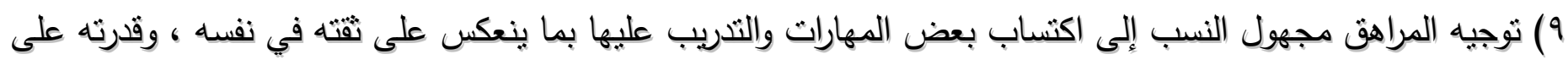

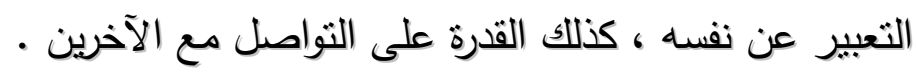

• (1) محاولة تذليل الصعوبات التي تحول دون التخفيف من حدة القلق الاجنماعي لدى المراهقين مجهولي النسب .

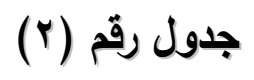

ثامناً : نتائج الدراسة :

يوضح درجات المجموعة التجريبية قبل التذخل ويعده على مؤشر الاضطرابات الفسيولوجية

\begin{tabular}{|c|c|c|c|c|c|c|c|c|c|c|c|}
\hline المرجح & مجموع الأوزان & نادراً & إلى حد & نعم & المرجح & مجموع الأوزان & نادراً & إلى حـ & نعم & العبارة & P \\
\hline.$\leqslant r$ & Tr & $1 T$ & 0 & - & .04 & rq & 1. & 0 & $r$ & 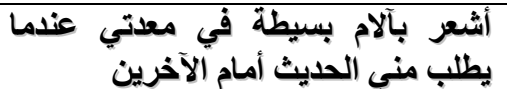 & 1 \\
\hline$\cdot . \leqslant \varepsilon$ & $r \varepsilon$ & $1 T$ & $\varepsilon$ & 1 & $.0 \mathrm{~V}$ & r) & 9 & 0 & $\varepsilon$ & ألثقع بنبضات قلبي مسموعة عند & $r$ \\
\hline$\Rightarrow \varepsilon \varepsilon$ & $r \varepsilon$ & - & 7 & Ir & .74 & $\mu \varepsilon$ & $r$ & 1. & 0 & الآخرين أشعر بالغثيان أثناء تعاملي مع & $r$ \\
\hline
\end{tabular}




\begin{tabular}{|c|c|c|c|c|c|c|c|c|c|c|c|}
\hline.. $\mathrm{HV}$ & $r$. & 17 & r & - &. .01 & $r \wedge$ & 11 & $\varepsilon$ & $r$ & أشعر بالدوخة عندما أتحدث مع الآخرين & $\varepsilon$ \\
\hline. .01 & rᄉ & 11 & $\varepsilon$ & r &. .71 & rv & 0 & V & 7 & الآخرين جسمي عذما أتحدث أمام & 0 \\
\hline .04 & rq & 1. & 0 & r &. $.7 \varepsilon$ & ro & $\varepsilon$ & 9 & 0 & لا أشعر بجفاف في الحلق عذما أواجه & 7 \\
\hline$\cdot . \leqslant 7$ & ro & 11 & $\checkmark$ & - & $.7 r$ & ए & V & 7 & 0 & لموقف جليدي خجلاً عذما أتعرض & $V$ \\
\hline. .09 & rt & 9 & $\varepsilon$ & 0 & $\therefore v$. & rᄉ & $\varepsilon$ & $\wedge$ & 1 & ألتصبب عرقَاً عندما يسألني المدرس عن & $\wedge$ \\
\hline$\because \leqslant \wedge$ & ry & r & r & IT &. .09 & rt & $\Lambda$ & 7 & $\varepsilon$ & الآخرين أصاب بالصداع عند الحليث مع & 9 \\
\hline. ro & 19 & iv & 1 & - &. .01 & rA & 11 & $\varepsilon$ & r & أشعر بالإجهاد عند بذل أقل مجهود & 10 \\
\hline.$r v$ & $r$. & 17 & $r$ & - & $.0 \mathrm{~V}$ & r & 9 & 。 & $\varepsilon$ & أشعر كثيراً بارتعاش في يدي & 11 \\
\hline$\cdot \varepsilon$ & rt & - & $\varepsilon$ & $1 \varepsilon$ & .94 & $\mu \varepsilon$ & r & 1. & 0 & أمام الآخرينة في صوتي عند الحليث & 14 \\
\hline- & rar & 119 & $\leq 4$ & 01 & - & ral & $\Lambda \varepsilon$ & va & or & المجموع & \\
\hline- & - & 00.1 & ri.r & rr.t & - & - & rA.9 & T.7 & $r \leq .0$ & النسبة & \\
\hline \multicolumn{5}{|c|}{$\% \leq 0.1$} & \multicolumn{5}{|c|}{$\%$ \%. } & القوة النسبية للمؤثر & \\
\hline
\end{tabular}

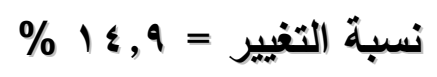

يتضح من الجدول السابق المرتبط بمؤشر الاضطرابات الفسيولوجية أن القوة النسبية للمؤشر قبل التخل ( • بـ\%) ،

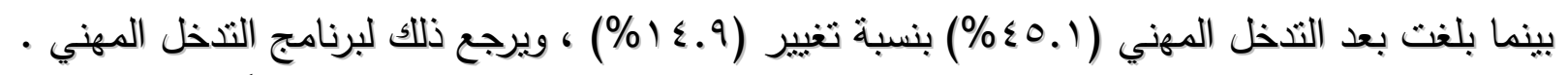

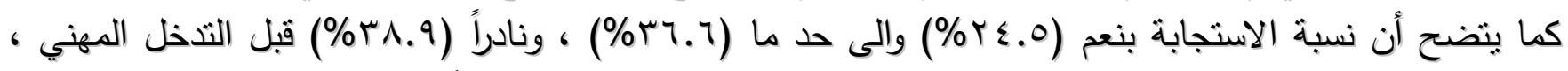

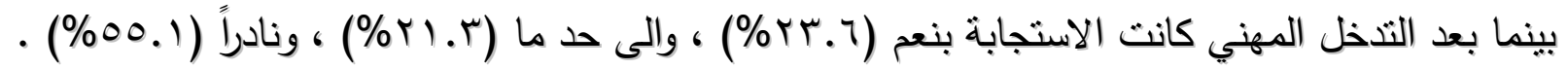

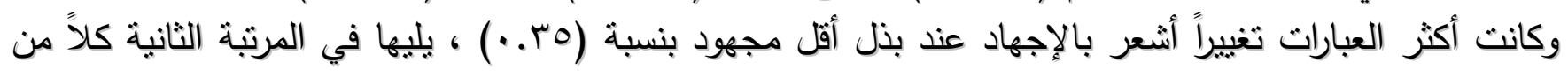

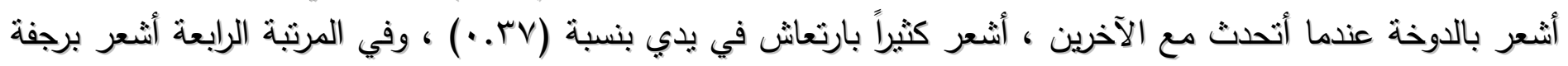

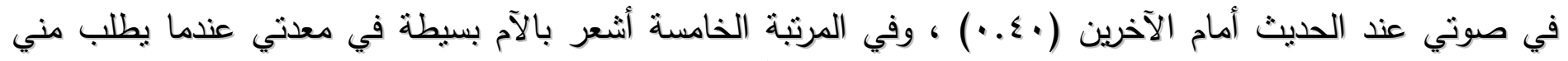

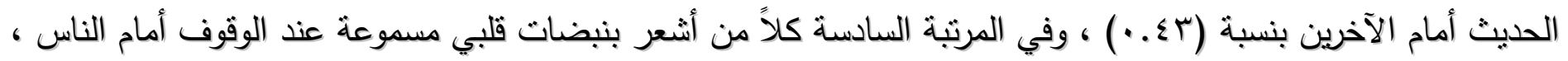

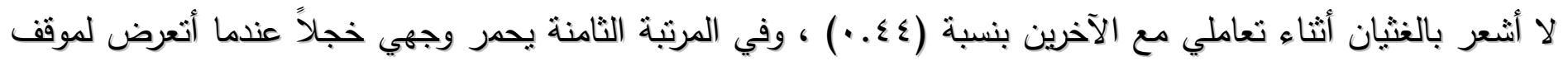

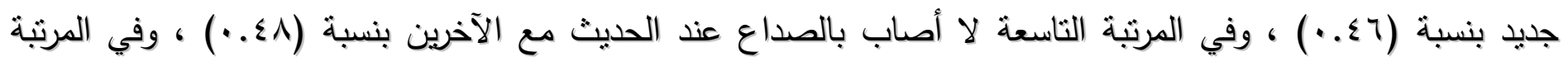

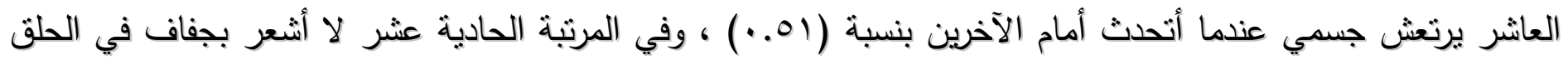
عندما أواجه الناس بنسبة (به. • (•) ، وفي المرثبة الثانية عثر أتصبب عرقاً عندما بسألني المدرس عن الواجبات المدرسية

\section{جدول رقم (r)}

يوضح درجات المجموعة التجريبية قبل التدخل ويعده على مؤثر ضعف الثقة في النفس

\begin{tabular}{|c|c|c|c|c|c|c|c|c|c|c|c|}
\hline المرجح & الأوزان & نادراً & إلى حا & نعم & المرجح & 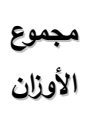 & نادراً & إلى حا & نعم & العبارة & r \\
\hline .01 & YA & 1. & 7 & $r$ & $.7 \varepsilon$ & ro & 0 & 9 & $\varepsilon$ & ينتخرون منين شعور أن الآخرين & 1 \\
\hline
\end{tabular}




\begin{tabular}{|c|c|c|c|c|c|c|c|c|c|c|c|}
\hline .04 & rq & 1. & 0 & r & 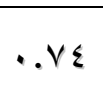 & $\varepsilon$ & r & $\wedge$ & v & عدم تقبا أقابل أشخاص جي جدا أخشى & r \\
\hline .00 & $\mu$. & r & 7 & 9 & $.7 \varepsilon$ & ro & $\varepsilon$ & 9 & o & الشخصي بالرضا عن مظهري & r \\
\hline $.0 \mathrm{~V}$ & M & 9 & 0 & $\varepsilon$ & $\because v \cdot$ & rA & $\varepsilon$ & $\wedge$ & 7 & في حساباتي أهاء الآخرين ولا أضعها & $\varepsilon$ \\
\hline .01 & rA & 11 & $\varepsilon$ & r &. $.7 r$ & $r \varepsilon$ & V & 7 & 0 & الآخرين أن تصرفاتي تثير ضحك & 0 \\
\hline$\cdot . \leqslant \varepsilon$ & $Y \varepsilon$ & 1 & $\varepsilon$ & r & .94 & rE & 0 & 7 & $\checkmark$ & لا أجد صعوبة في تحقيق أهدافي & 7 \\
\hline$\because v$ & rی & $\varepsilon$ & $\wedge$ & 7 &.$\vee \vee \varepsilon$ & $\varepsilon$ & r & $\wedge$ & $\checkmark$ & أشعر أنني أقل قدراً من الآخرين & $\checkmark$ \\
\hline .04 & rq & 1. & 0 & $r$ & $\therefore$ vo & \&1 & $\varepsilon$ & 0 & 9 & الثزارعج عندما ينظر إلى الناس في & $\wedge$ \\
\hline $.0 \mathrm{~V}$ & M & $\varepsilon$ & 0 & 9 & $\because V r$ & rq & 7 & 9 & r & أثق في قدراتي وإمكانياتي & 9 \\
\hline$\cdots \leqslant 1$ & rr & $1 \varepsilon$ & $\varepsilon$ & - &. .09 & re & $\wedge$ & 7 & $\varepsilon$ & عينتيني شعور أن الآخرين يعرفون & 1. \\
\hline. .01 & rA & 1. & 7 & r &. .71 & rv & 0 & V & 7 & بصورة أنجابية زملائي لا يتحدثون عني & 11 \\
\hline .00 & $\mu$. & $\varepsilon$ & $\varepsilon$ & 1 . & $\because V \varepsilon$ & $\varepsilon$ & 9 & $\varepsilon$ & 0 & أشطعر أنتي شخص غير نافع على & Ir \\
\hline- & $r \leqslant \Lambda$ & 9. & ir & $7 \varepsilon$ & - & $\leqslant \leqslant 0$ & 4 & 10 & 71 & المجموع & \\
\hline- & - & $\& 1 . V$ & r^.V & r9.7 & - & - & ra.1 & rq. & M. 1.0 & النسبة & \\
\hline \multicolumn{5}{|c|}{$\% \circ r . v$} & \multicolumn{5}{|c|}{$\%$ \%. レ } & القوة النسبية للمؤثر & \\
\hline & & & & & & $=$ & ل & & & & \\
\hline
\end{tabular}

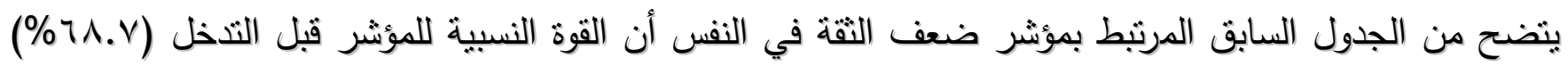

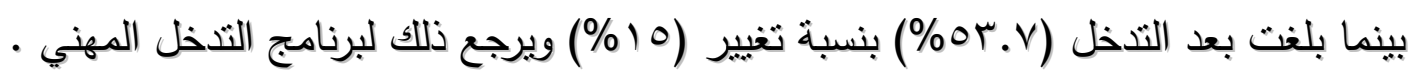

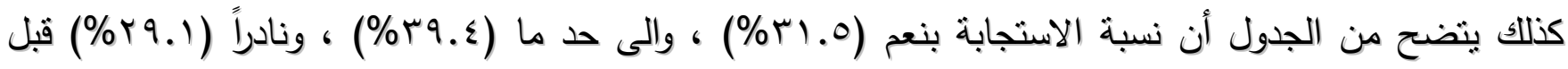

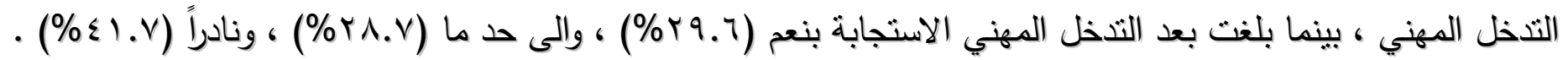
وكانت أكثر العبارات تغييراً ينتابني شعور أن الآخرين يعرفون عيوبي في المرتبة الأولى بنسبة (اء...) ، وفي المرتبة الثانية لا أجد صعوبة في تحقيق أهدافي بنسبة (عـ..) ، وفي المرتبة الرابعة كل من ينتابني شعور أن الآخرون يسخرون مني ، أثعر أن تصرفاتي ثثير ضحك الآخرين ، ادراك أن زملائي لا يتحدثون عني بصورة ايجابية بنسبة (10. •) ، وفي المرتبة السادسة كلاً من عندما أقابل أثخاص جدد أخثى عدم تقبلهم لي ، وانزعج عندما بنظر إلى الناس في الثنارع بنسبة (به. • ) ، وفي المرثبة الثامنة كلاً من أشعر بالرضا عن مظهري ، أثنعر أنني شخص غير نافع على الاطلاق بنسبة

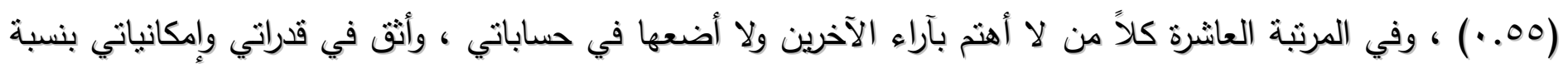

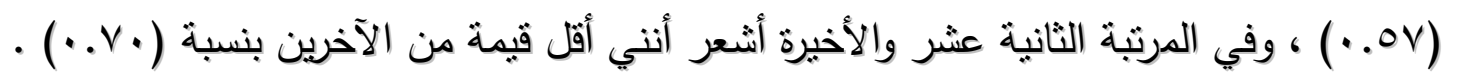

\section{جدول رقم (؛ )}

يوضح درجات المجموعة التجريبية قبل التدخل ويعده على مؤشر صعوية التواصل والتعبير عن النفس مع الآخرين

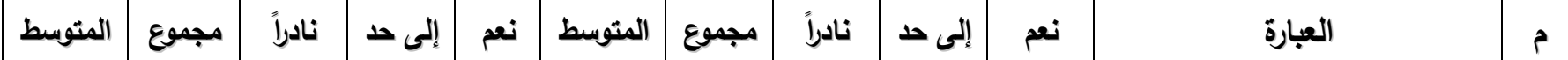




\begin{tabular}{|c|c|c|c|c|c|c|c|c|c|c|c|}
\hline المرجح & الأوزلن & & ما & & المرجح & الأوزلن & & ما & & & \\
\hline . & rq & 1. & 0 & $r$ & .71 & rv & 0 & V & 7 & مجموعة من الناس وجودي بين & 1 \\
\hline .01 & rᄉ & 9 & $\wedge$ & 1 & $\because v$ & rᄉ & $\varepsilon$ & $\Lambda$ & 7 & عرض موضبياً عندما يطب مني & $r$ \\
\hline .07 & r. & 0 & r & 11 &. Vo & \&1 & 9 & 0 & $\varepsilon$ & لا أجد صعوبة في البدء بالحديث & $r$ \\
\hline$\because \leqslant \leqslant$ & rs & Ir & 7 & - & $.7 \varepsilon$ & ro & $\varepsilon$ & 9 & 0 & ألتعثم في كلامي عند مواجهة & $\varepsilon$ \\
\hline .01 & rA & 11 & $\varepsilon$ & $r$ & .71 & rv & 0 & V & 7 & قلق وغير مرتآح في حفلة أشعر أنني & 0 \\
\hline$\because \leqslant \leqslant$ & rs & 1 & $\varepsilon$ & IT & $.7 r$ & r & 0 & 7 & V & أنتمتع بالحديث أمام مجموعة من & 7 \\
\hline $.0 r$ & rq & 11 & $r$ & $\varepsilon$ & $\because v$ & rᄉ & $\varepsilon$ & $\wedge$ & 7 & أميل إلى العزلة والابتعاد عن & $V$ \\
\hline $.0 \mathrm{~V}$ & r & 9 & 0 & $\varepsilon$ & $\because V \varepsilon$ & $\varepsilon$. & $r$ & $\Lambda$ & V & الآخرين لدي القرة على مواجهة & $\Lambda$ \\
\hline. .01 & YA & 1 & $\Lambda$ & 9 &.$V Y$ & rq & 7 & 9 & $r$ & أبدأ بتكوين صداقات جديدة & 9 \\
\hline..$\leqslant \Lambda$ & $r y$ & 11 & 7 & 1 &. $.7 T$ & rs & V & 7 & 0 & على التحدث خائفاً عدما يصبح لزامباً & 1. \\
\hline $.0 r$ & rq & 9 & 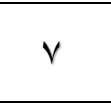 & r & $\because v \cdot$ & rᄉ & $\varepsilon$ & $\wedge$ & 7 & أمام الغرباء علي التعبير عن رأيي & 11 \\
\hline 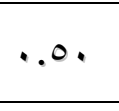 & rV & ir & r & $r$ &.$V Y$ & rq & ○ & 0 & $\wedge$ & أحراج لي أمام الآخرين تصبين تصرفاتي & IT \\
\hline- & rrr & 1.1 & 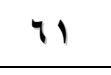 & $0 \leq$ & - & $\leqslant 0$. & $\pi$ & ^ & 79 & المجموع & \\
\hline- & - & $\leq 4 . V$ & rA.r & ro & - & - & r^.r & ra.1 & $r 1.9$ & النسبة & \\
\hline \multicolumn{5}{|c|}{$\% 01.4$} & \multicolumn{5}{|c|}{$\%$} & القوة النسبية للمؤثر & \\
\hline \multicolumn{12}{|c|}{ ن 1^ = نسبة التغيير } \\
\hline
\end{tabular}

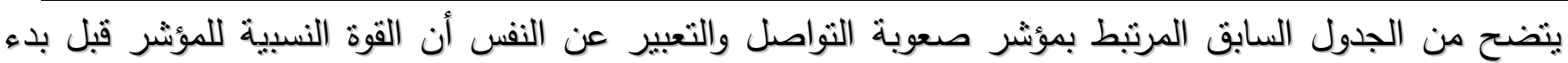

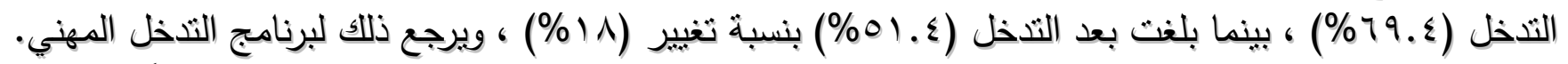

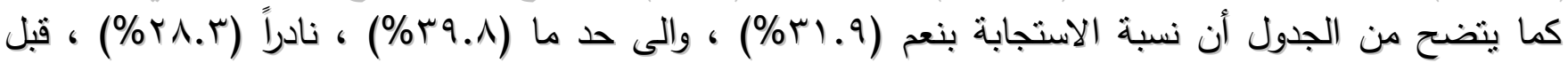

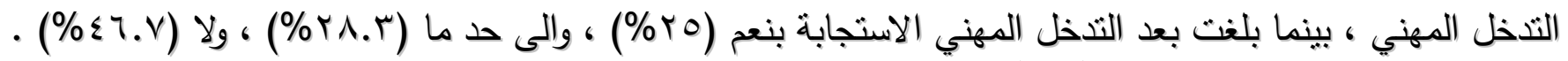

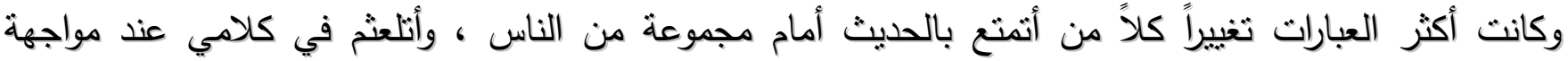

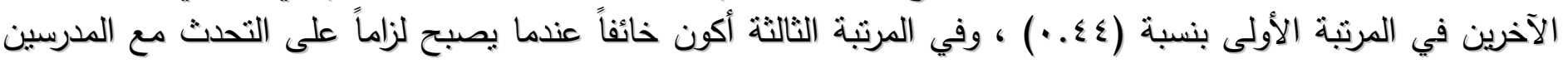

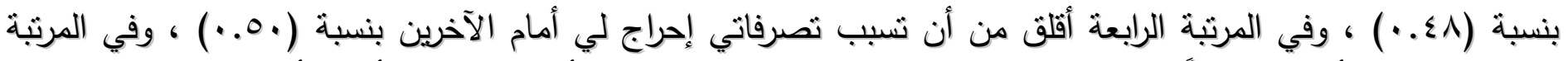

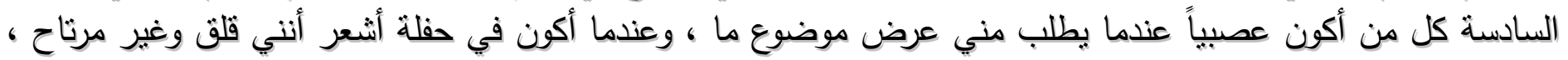

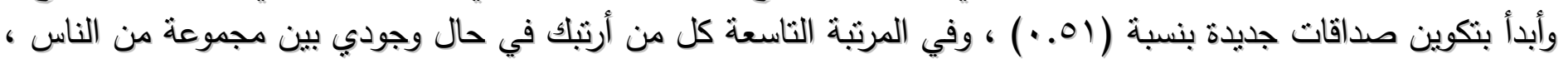

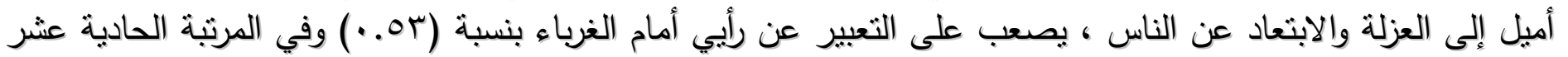

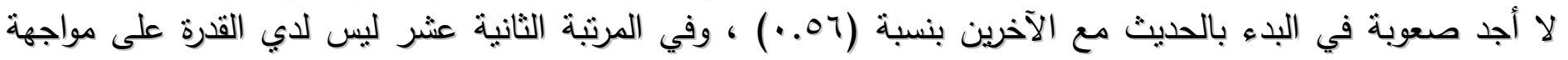

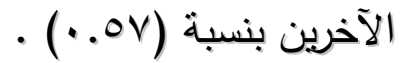




\section{جدول رقم (0)}

يوضح الدلالة الإحصائية على مقياس القبلي والبعدي للمجموعة التجريبية على مقياس القلق الاجتماعي

\begin{tabular}{|c|c|c|c|c|}
\hline ت ت الجدولية & ت المحسوية & الانحراف المعياري & الوسط الحسابي & المؤثر \\
\hline \multirow{3}{*}{$\begin{array}{c}=(\cdots 0, \mathrm{lv}) \\
1 . v \leq .\end{array}$} & $0 . \xi$ & 11.9 & 0.0 & الاضطرابات الفسيولوجية \\
\hline & $\varepsilon . \wedge$ & $r \cdot .0$ & $0 . r$ & صعوية الثقة في النفس \\
\hline & 0.9 & rr.s & 7.0 & صعوية التواصل والتعبير عن النفس مع الآخرين \\
\hline- & r.Ao & 1710 & IV.द & المقياس ككل \\
\hline
\end{tabular}

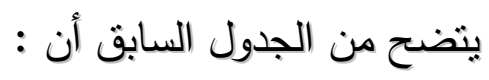

- بالنسبة لمؤشر الاضطرابات الفسيولوجية نجد أن قيمة ت المحسوبة أكبر من قيمة ت الجدولية ، حيث بلغت قيمة ت

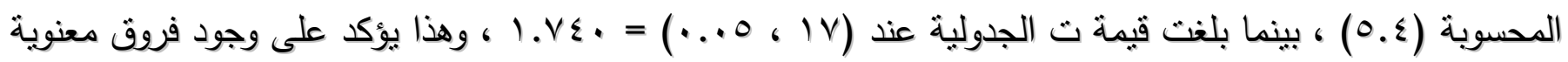

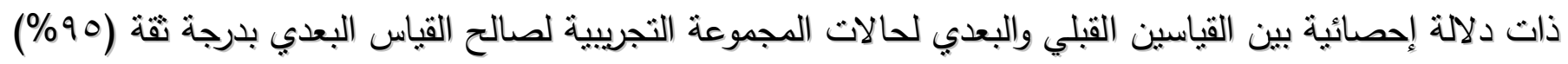

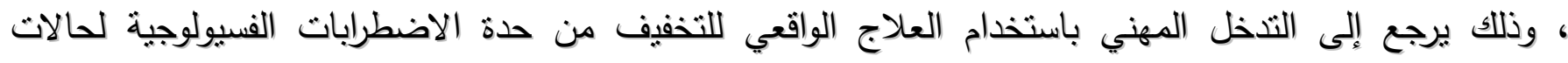

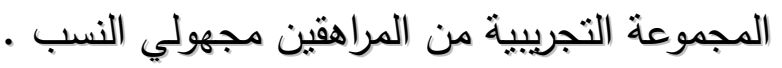

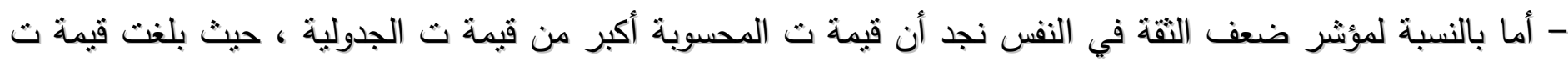

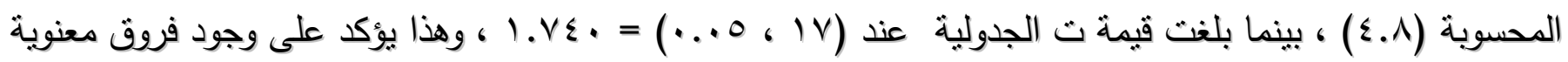

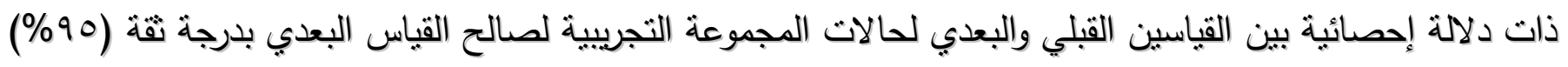

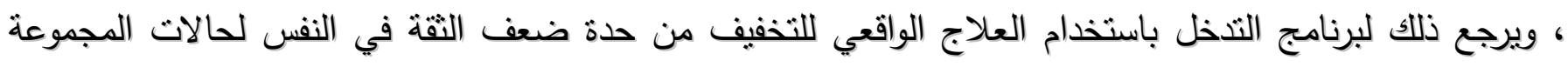

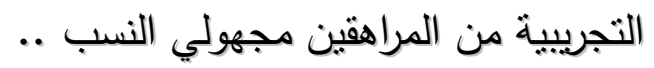

- كذلك بالنسبة لمؤشر صعوبة التواصل والتعبير عن النفس نجد أن قيمة ت المحسوبة أكبر من قيمة ت الجدولية ، حيث

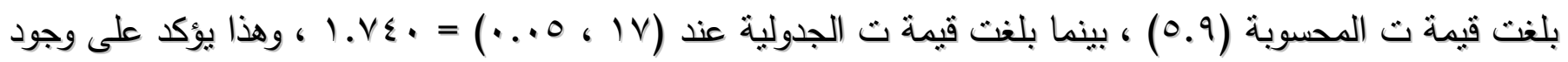

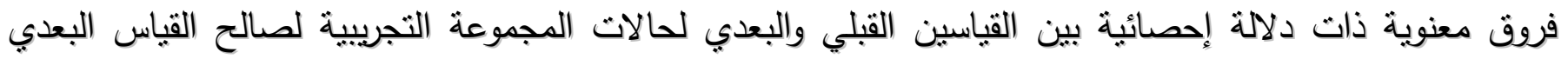
بدرجة ثقة (09\%) ، وذللك يرجع إلى التذخل المهني باستخدام العلاج الواقعي للتخفيف من صعوبة التواصل والتعبير

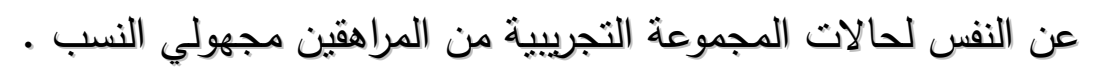

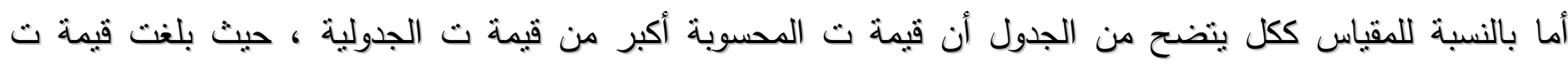

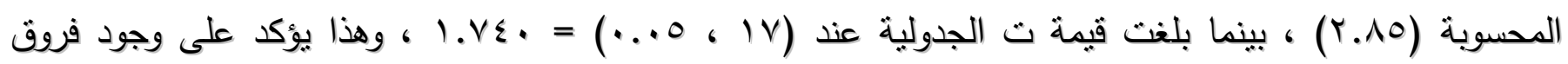

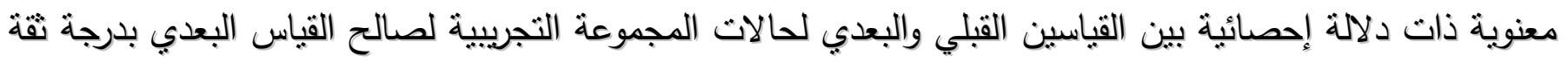
(90\%) ، وذللك يرجع إلى ممارسة العلاج الواقعي في خدمة الفرد للتخفيف من حدة القلق الاجتماعي لحالات المجموعة التجريبية من المراهقين مجهولي النسب . 
تاسعاً : تفسير نتائج الاراسة :

توصلت الدراسة إلى صحة الفرد الرئيسي للاراسة ومؤداه :

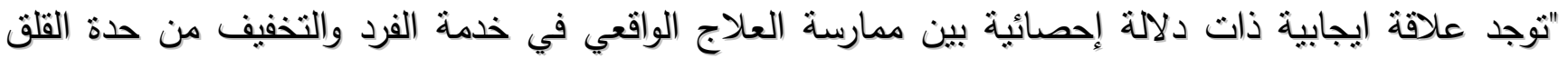

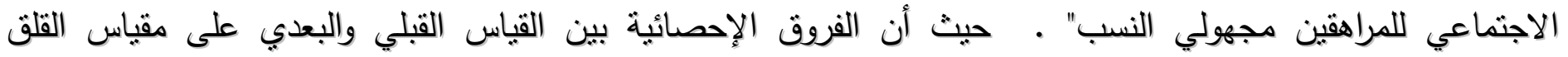

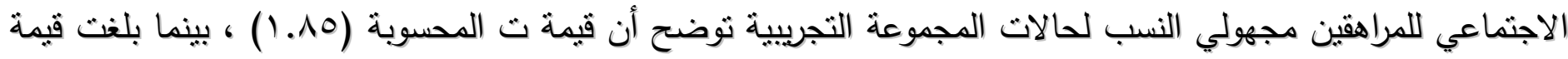

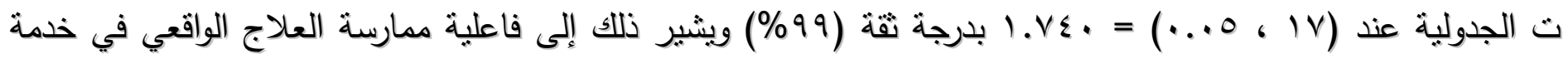
الفرد والتخفيف من حدة القلق الاجتماعي للمراهقين مجهولي النسب .

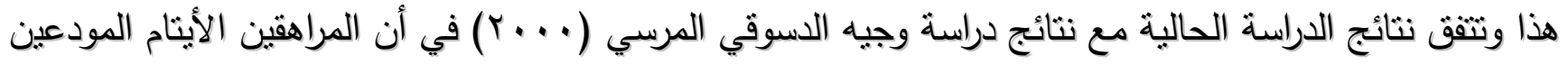

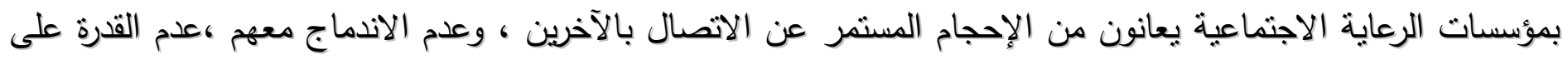

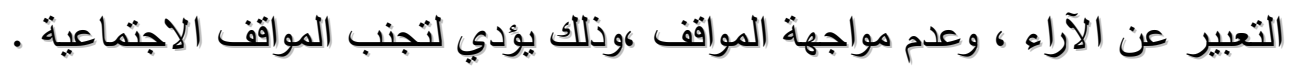

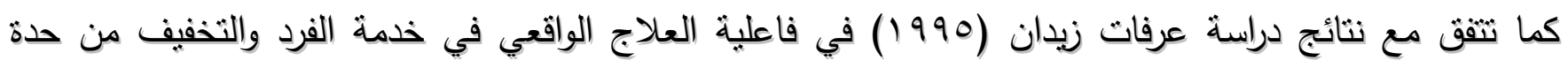

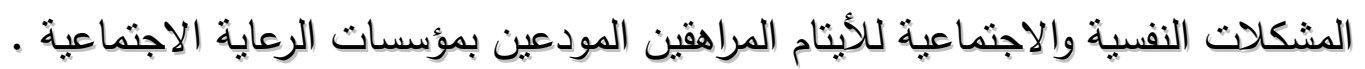

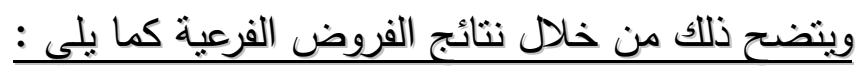
أ- أثتثت نتائج الدراسة صحة الفرض الأول ومؤداه : " ثوجد علاقة ايجابية ذات دلالة إحصائية بين ممارسة العلاج الواقعي في خدمة الفرد والتخفيف من حدة التهات

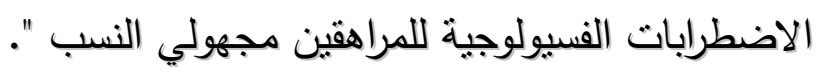

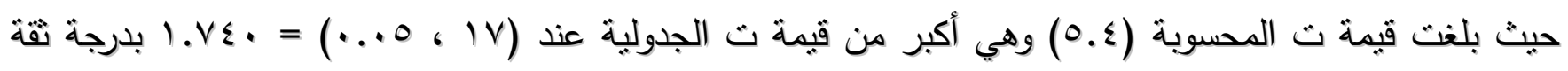

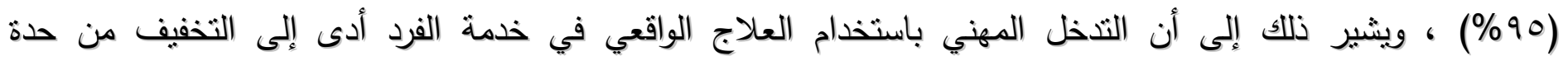
الاضطرابات الفسيولوجية للمراهقين مجهولي النسب . وتتمثل الاضطرابات الفسيولوجية للقلق في أعراض جسمية تتمثل في زيادة النبض ، زيادة دقات القلب ، مشاكل في

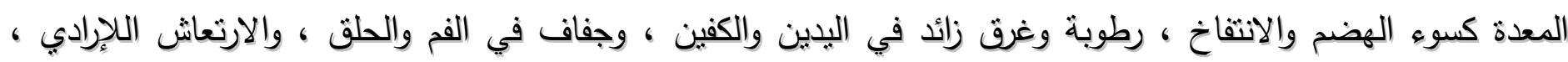

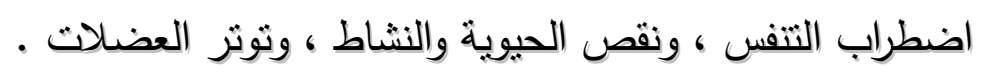
وتتفق نتائج الدراسة الحالية مع ما ذكره مجدي أحمد عبد الله (997 (199 أن القلق الاجتماعي يسبب أعراضاً بدنية

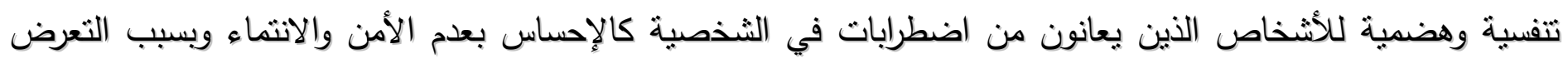

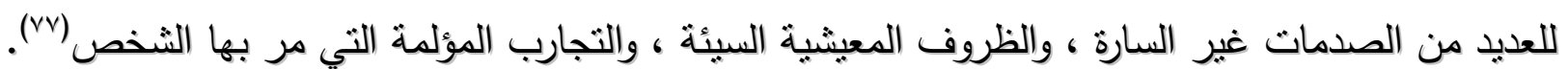

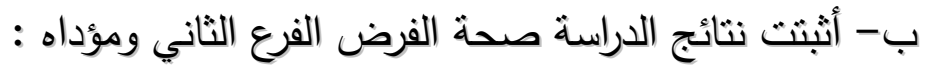


"توجد علاقة ايجابية ذات دلالة إحصائية بين ممارسة العلاج الواقعي في خدمة الفرد والتخفيف من حدة ضعف النقة

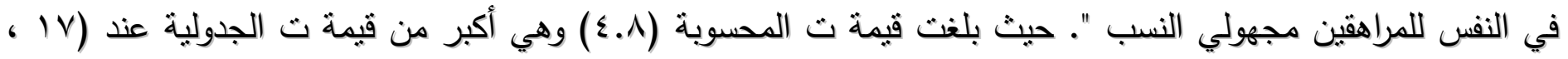

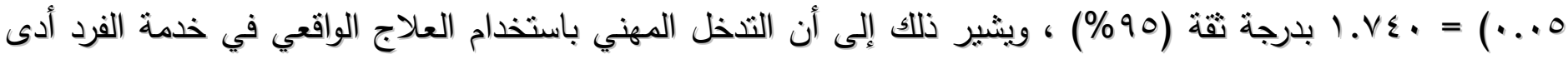
إلى التخفيف من حدة ضعف الثقة في النفس للمراهقين مجهولي النسب . ويتمنل ضعف الثقة بالنفس في الثعور بالسلبية والتردد ، وضعف الثقة التي تجعل المراهق مجهول النسب بتصرف وكأنه مراقب مما حوله فتصبح تحركاته وتصرفاته مخالفة لطبيعته . وقد أشارت نتائج العديد من الدراسات السابقة إلى أن مجهولي النسب يعانون من العديد من الاضطرابات الانفعالية أهمها التونز ،والخجل ،والانطواء ،والعزلة ، وتذني مفهوم الذات، والثعور بالاغتراب ، وضعف الثقة في النفس ، وهذا يرجع إلى الظروف التي من خلالها ثم التحاقهم بالمؤسسات الإيوائية . هذا كما أن المناخ المؤسسي يؤثز في ضعف الثقة في النفس لدى المراهقين مجهولي النسب وذلك من خلال عدم إعطاء الفرصة للمراهق للتعبير عن نفسه وعدم تشجيعه على طرح الأسئلة والاستفسارات أو الرفض والإدانة له عند التعبير عن بعض الانفعالات ، وكذلك تعرضه للإحباط الثديد ، أو عدم الثعور بالأمان بالإضافة إلى الخبرات السلبية التي يتعرض لها في المؤسسة . ج- أثنتت نتائج الدراسة صحة الفهة الفرض الفرعي الثالث ومؤداه : " توجد علاقة ايجابية ذات دلالة إحصائية بين ممارسة العلاج الواقعي في خدمة الفرد والتخفيف من حدة صعوبة التواصل والتعبير عن النفس مع الآخرين للمراهقين مجهولي النسب ".

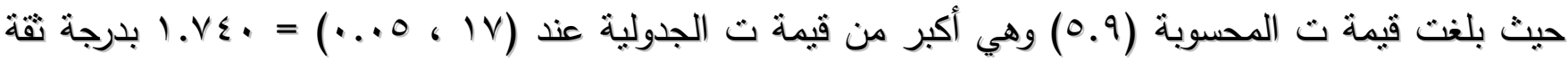
(90\%) ، ويشير ذلك إلى أن التذخل المهني باستخدام العلاج الواقعي في خدمة الفرد أدى إلى التخفيف من حدة صعوبة التواصل والتعبير عن النفس للمراهقين مجهولي النسب . وتتمثل صعوبة التواصل والتعبير عن النفس مع الآخرين في صعوبة الاتصال والمواجهة مع ما يتعرض إليه المراهق مجهول النسب ،وصعوبة التعبير عن ذاته في الوسط الذي يعيش فيه ، وعدم شعوره بالارتياح تجاه نفسه . حيث أن استخدام العلاج الواقعي في خدمة الفرد أدى إلى خفض المظاهر الاجتماعية للقلق الاجتماعي المتمثلة في تفضيل العزلة والبعد عن الزملاء في المؤسسة ، وصعوبة تكوين صداقات جديدة ، والثعور بالخجل عندما ينواجد المراهق وسط مجموعة من الناس والثعور بالنقص وعدم الرغبة في الظهور في الأماكن العامة واللقاءات الجماعية .

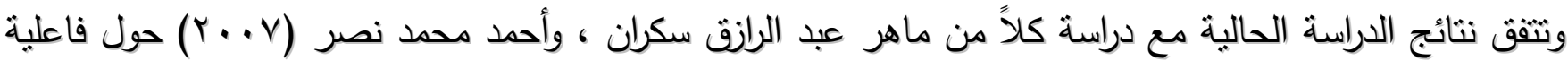
العلاج الواقعي في خدمة الفرد في التخفيف دن حدة قلق التفاعل ويشمل قلق العلاقات الشخصية ، وقلق المواجهة ويشمل قلق الحديث وقلق الاتصال لدى طلاب الجامعة المكفوفين . 


\section{المراجع}

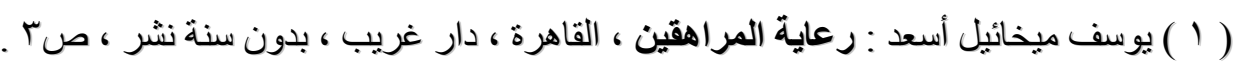

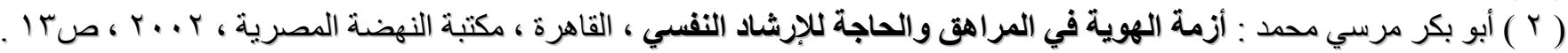

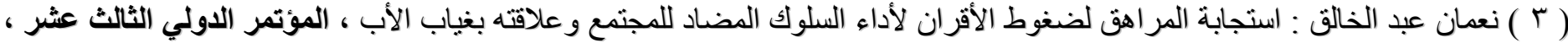

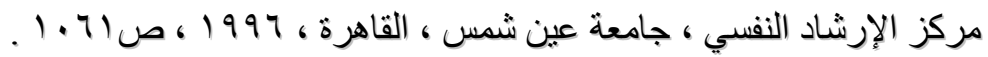

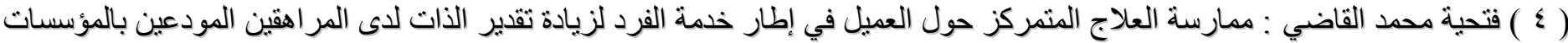

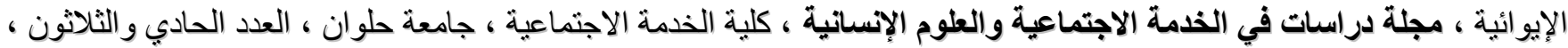

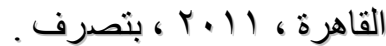

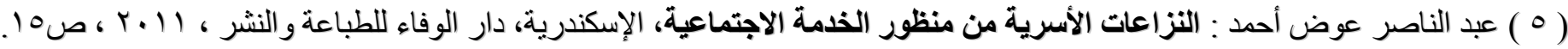

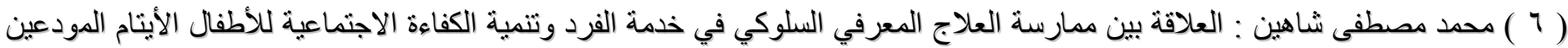
بالمؤسسات الإيو ائية ، المؤتمر العلمي الدولي الرابع والعثرين للذدمة الاجتماعية ، كلية الخدمة الاجتماعية ، جامعة حلوان ، القاهرة ،

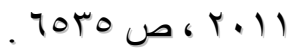

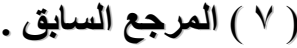

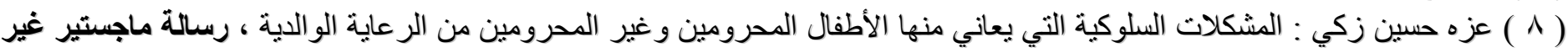

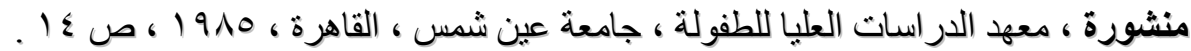

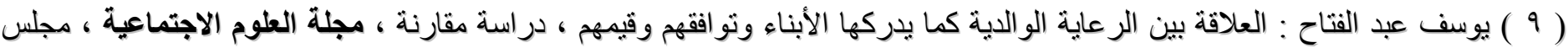

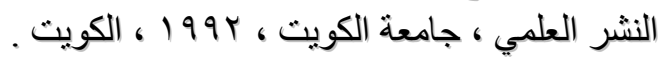

(10) Barbara Tiyard \& Judith Ross : the effect of early institutional rearing on the behavior problems, New York, Journal of chilled psychology, no., (16), 1995 .

(11) Johnlynos \& Katherine Schafeer : mental health and dangerousness characteristics and outcomes of children and adolescents in residential placements, journal of child and family studies, vol., (9), no., (1) 2000 .

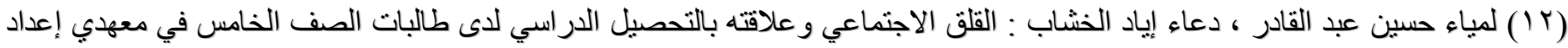

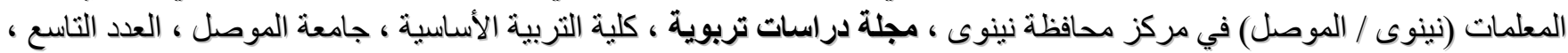

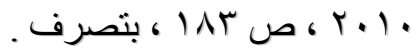

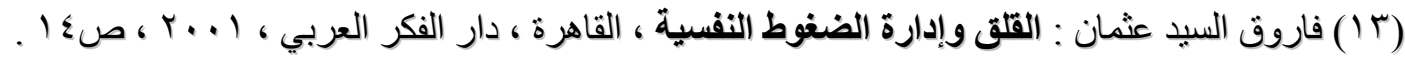

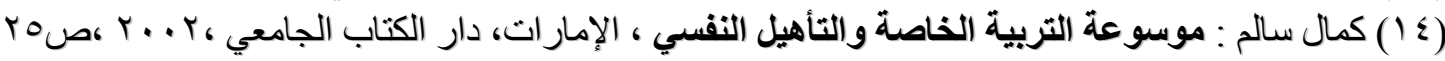

(15) Marie Robin \& Robert J., : the interrelationship of social anxiety with anxiety depression, locus of control, ways of coping and ego strength amongst university students, journal article, 2009, p: 24 .

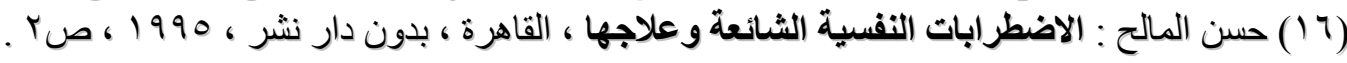




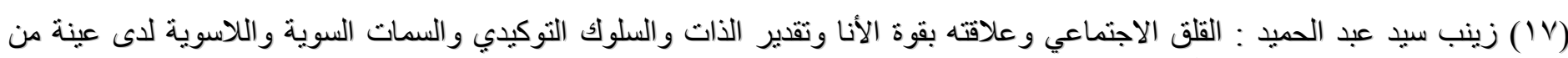

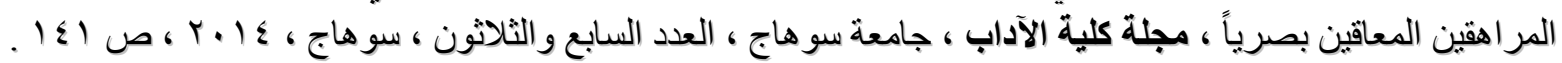

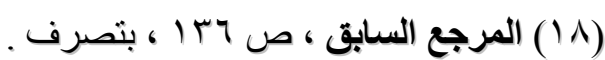

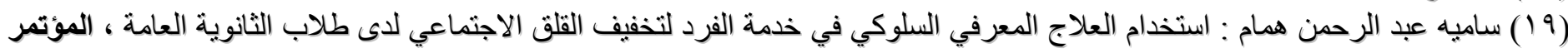

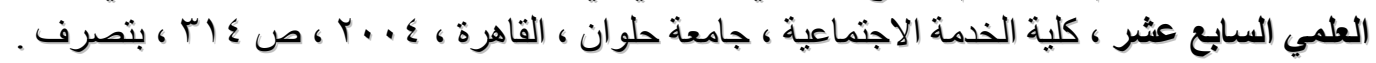

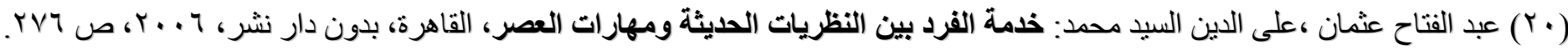

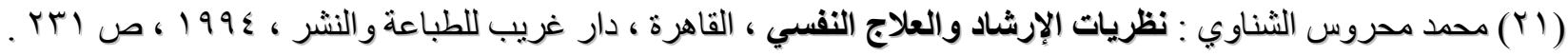

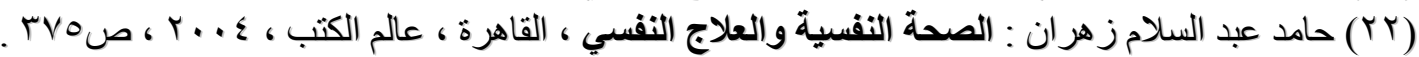

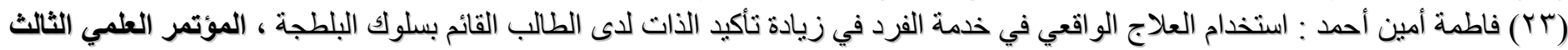

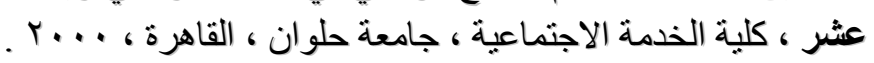

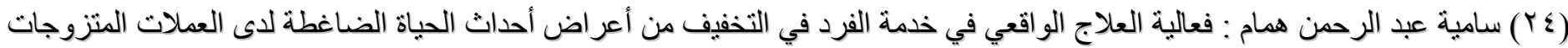

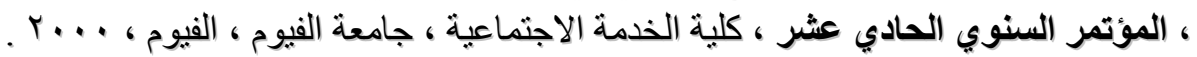

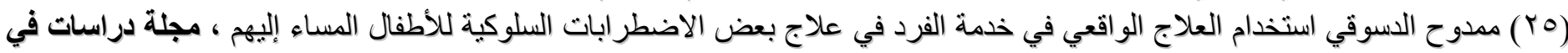

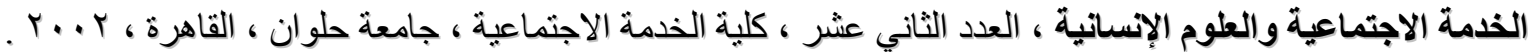

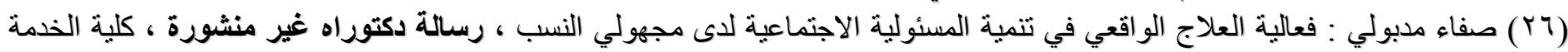

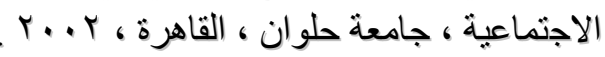

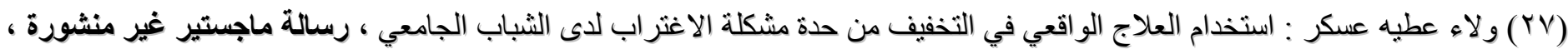

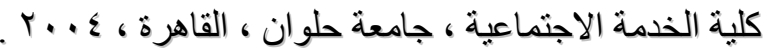

(YA)

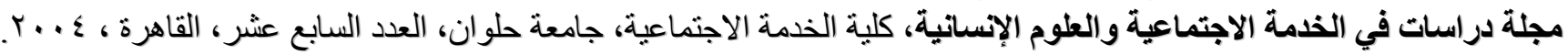

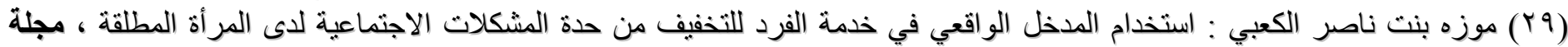

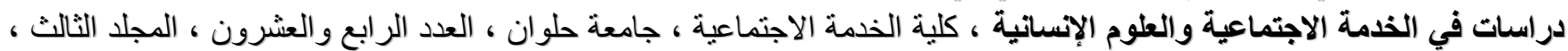

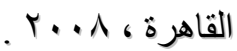

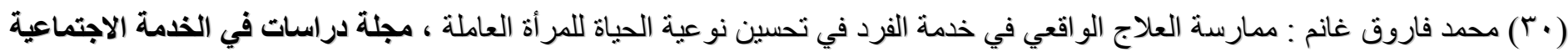

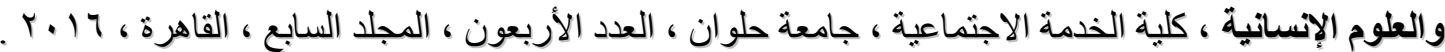

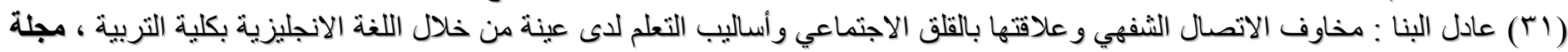

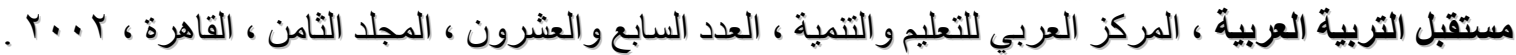

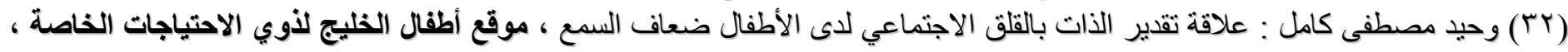

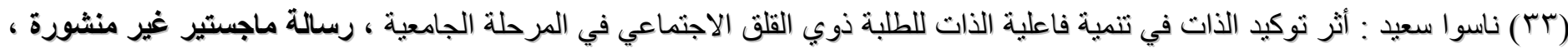

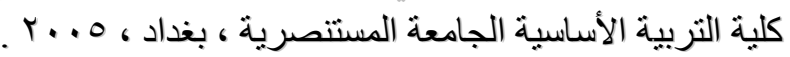
(ع ب) فتحية عبد العال : القلق الاجتماعي لدى ضحايا مشاغبة الأقران في البيئة المدرسية ، مجلية كلية التربية ، جامعة بنها ، العدد الثامن

(35) Bensink, R, : Internet use identity development and social anxiety among young adults, psychological science, journal article, vol, 29 (6), 2006.

(36) Epkins C., : affectice confounding in social anxiety and dysphoria in children, child, mother and father reports of internalizing behaviors, journal of social clinical psychology, vol., (15) 4, 2007 .

(rV) عبد الر ازق جدوع محمد : القلق الاجتماعي لدى النساء المهرات في محافظة ديالي ، مجلة الفتح ، كلية الثربية الأساسية ، جامعة ديالي ،

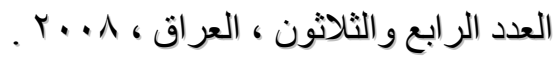

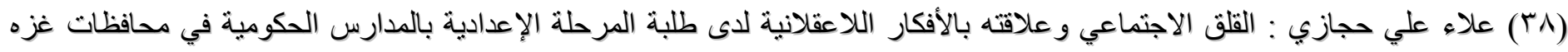

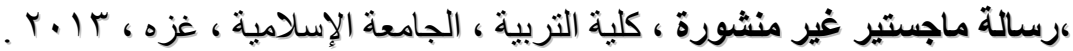


(40) Cohen Yecheskiet : attachment as the basis psychopathological development and residential treatment, journal psychoanalytic study of the child, vol., (52), 1997.

(41) Peter H. Wollf \& Geberemeskel Fesseha : orphanages part of the problem of the solution, Boston, The American of psychiatry, vol., 155, 1998 .

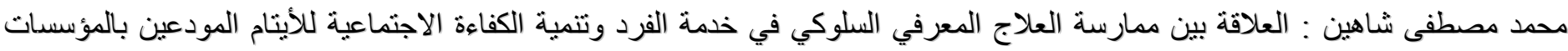

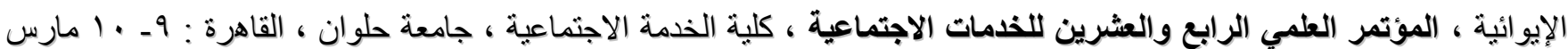

(r § ) هناء أحمد أمين : فعالية العلاج المتمركز حول العميل في خدمة الفرد في تعديل مفهوم الذات للمراهقات مجهو لات النسب ، رسالة دكتوراه

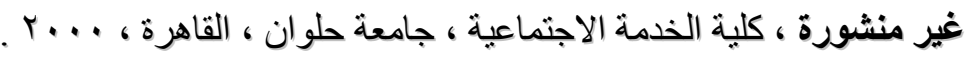

(43) Cloudia Fonseca : orphanages, foundlings, foster mothers : the system of circulation in a Brazilian squatrer settlement anthropological-quarterly, journal of vocational behavior, vol., (59), 2003.

(44) Edmiston Barid : the followed care in the accommodation institute on the longer children, Alaska, university of Pennsylvania, journal article , 2004.

(0؟) صفاء عادل مدبولي : ممارسة العلاج المعرفي السلوكي في خدمة الفرد للتخفيف من مشكلة اضطراب العلاقات الاجتماعية للأطفال

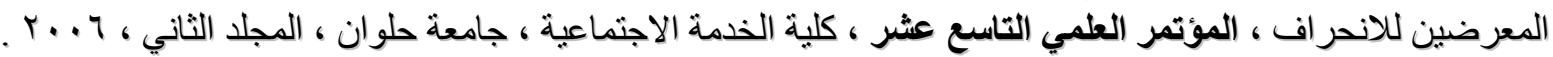

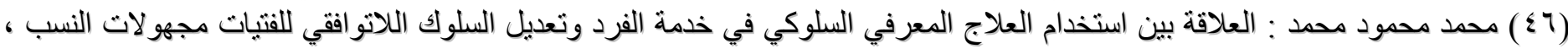

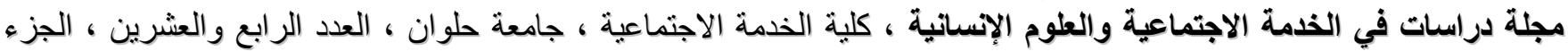

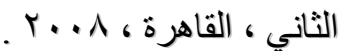

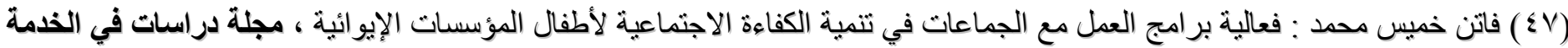

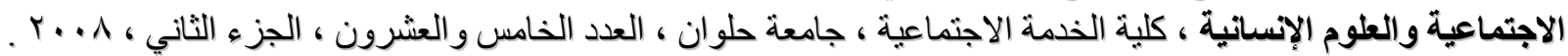

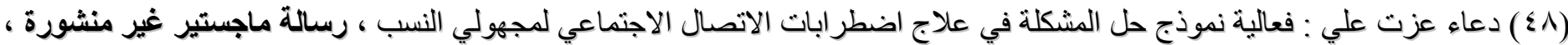

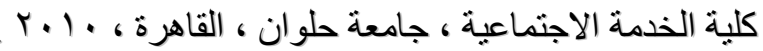

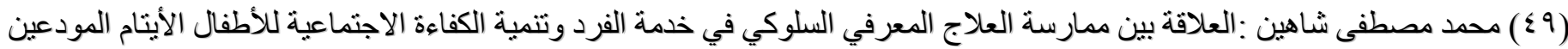

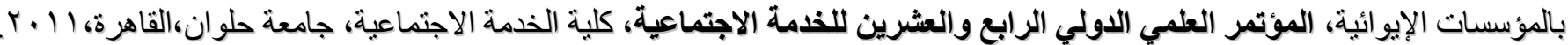

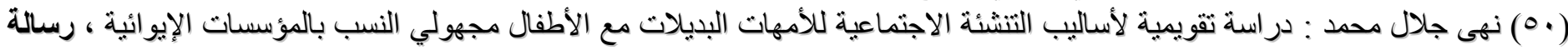

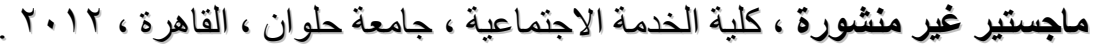

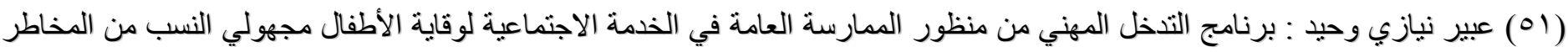

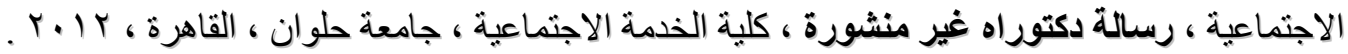

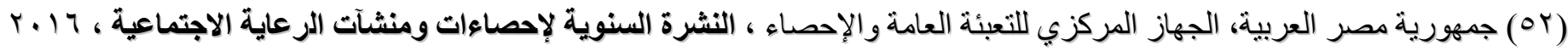

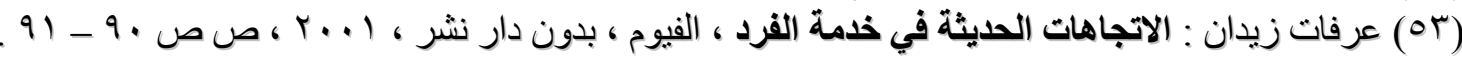

(54) Govery Gerald : theory and practice of group counseling, California, brooks cole publishing company, 1987, p: 752 .

(55) Charles Zastrow : Ghoic theory, the w.g., institute and the Austin center for realty therapy and quality school, support, New York, 2003, p : 452 .

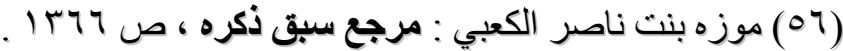

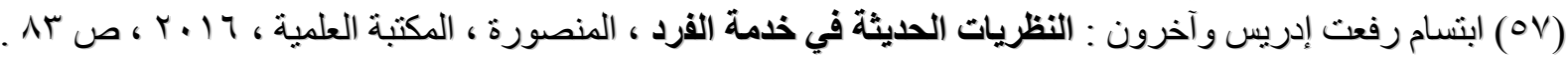

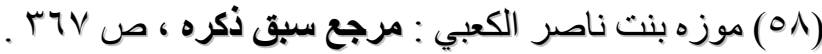

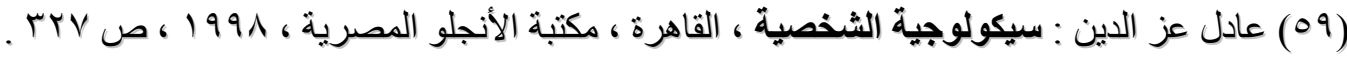

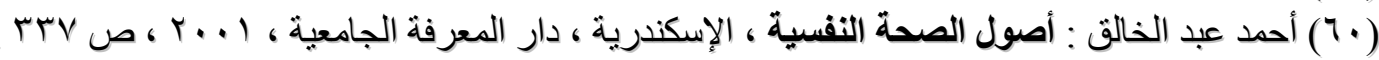

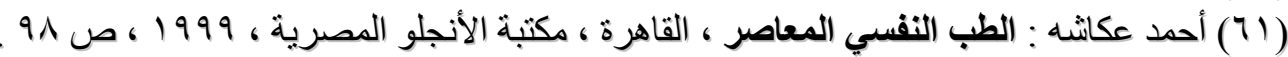


(זT) سلوى جمال : أثر البرامج الإرشادية في خفض القلق الاجتماعي لدى الطلبة الجدد في المعهد التقني ، رسالة دكتوراه غير منشورة ، كلية

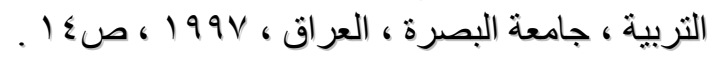

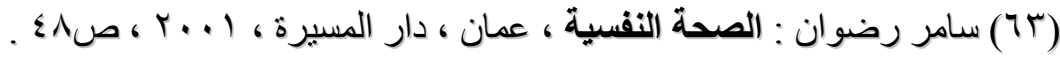

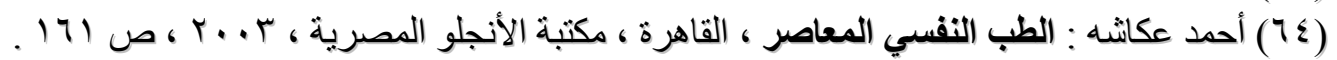

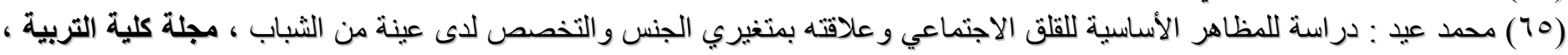

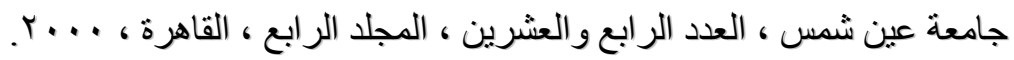

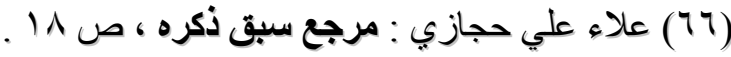

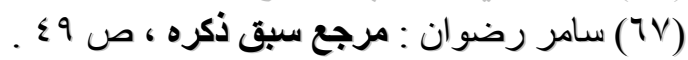

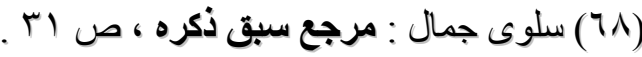

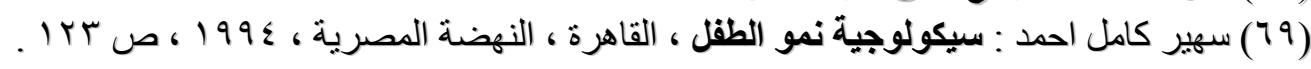

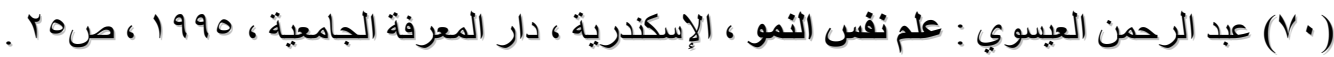

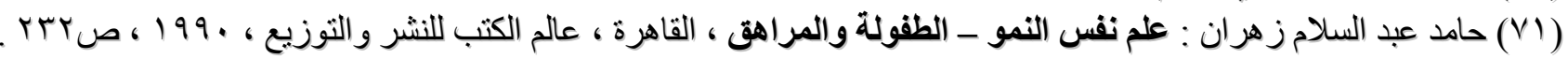

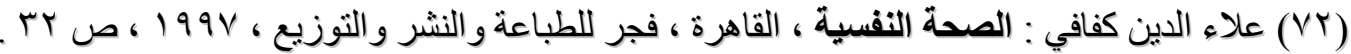

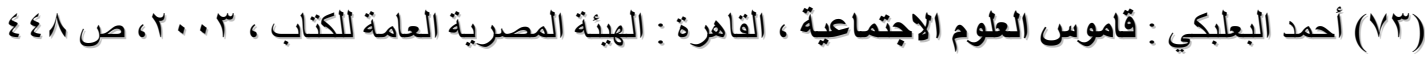

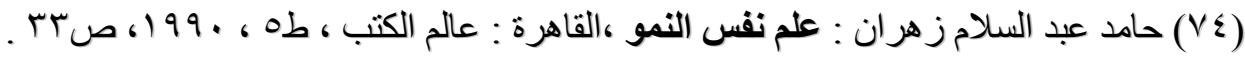

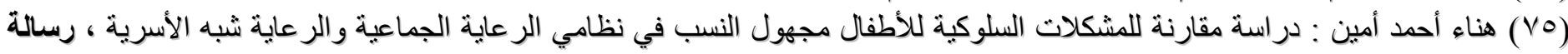

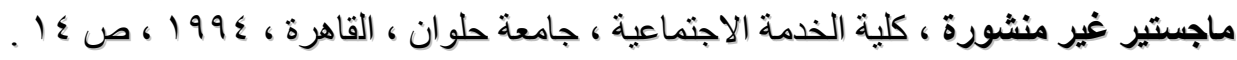

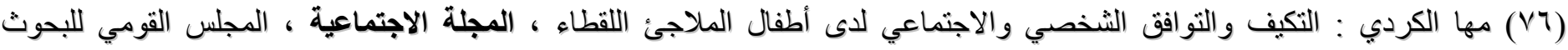

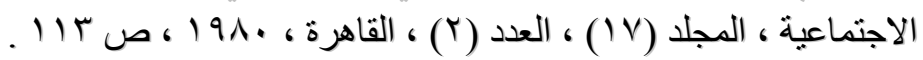

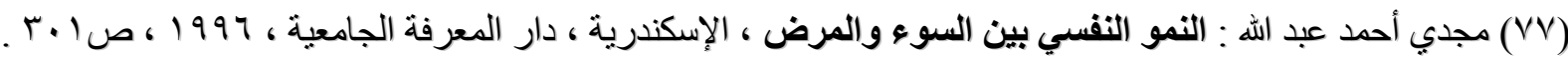

